\title{
Orexin Gene Transfer into Zona Incerta Neurons Suppresses Muscle Paralysis in Narcoleptic Mice
}

\author{
Meng Liu, ${ }^{1 \star}$ Carlos Blanco-Centurion, ${ }^{1 \star}$ RodaRani Konadhode, ${ }^{1}$ Suraiya Begum, ${ }^{1}$ Dheeraj Pelluru, ${ }^{1}$ \\ Dmitry Gerashchenko, ${ }^{1}$ Takeshi Sakurai, ${ }^{2}$ Masashi Yanagisawa, ${ }^{3}$ Anthony N. van den Pol, ${ }^{4}$ and Priyattam J. Shiromani \\ ${ }^{1}$ Veterans Affairs Boston Healthcare System and Harvard Medical School, West Roxbury, Massachusetts 02132, ${ }^{2}$ Department of Molecular Neuroscience \\ and Integrative Physiology, Faculty of Medicine, Kanazawa University, Kanazawa 920-8640, Japan, ${ }^{3}$ Howard Hughes Medical Institute and University of \\ Texas Southwestern Medical Center, Dallas, Texas 75390, and ${ }^{4}$ Department of Neurosurgery, School of Medicine, Yale University, New Haven, Connecticut \\ 06520
}

Cataplexy, a sudden unexpected muscle paralysis, is a debilitating symptom of the neurodegenerative sleep disorder, narcolepsy. During these attacks, the person is paralyzed, but fully conscious and aware of their surroundings. To identify potential neurons that might serve as surrogate orexin neurons to suppress such attacks, the gene for orexin (hypocretin), a peptide lost in most human narcoleptics, was delivered into the brains of the orexin-ataxin-3 transgenic mouse model of human narcolepsy. Three weeks after the recombinant adenoassociated virus (rAAV)-mediated orexin gene transfer, sleep-wake behavior was assessed. rAAV-orexin gene delivery into neurons of the zona incerta $(\mathrm{ZI})$, or the lateral hypothalamus $(\mathrm{LH})$ blocked cataplexy. Orexin gene transfer into the striatum or in the melanin-concentrating hormone neurons in the ZI or LH had no such effect, indicating site specificity. In transgenic mice lacking orexin neurons but given rAAV-orexin, detectable levels of orexin-A were evident in the CSF, indicating release of the peptide from the surrogate neurons. Retrograde tracer studies showed that the amygdala innervates the ZI consistent with evidence that strong emotions trigger cataplexy. In turn, the ZI projects to the locus ceruleus, indicating that the ZI is part of a circuit that stabilizes motor tone. Our results indicate that these neurons might also be recruited to block the muscle paralysis in narcolepsy.

\section{Introduction}

Narcolepsy is a neurological sleep disorder in which one characteristic symptom is a sudden unexpected muscle paralysis, referred to as cataplexy (Aldrich, 1993; Mignot, 1998). These attacks are usually triggered by strong emotions such as laughter or anger (Siegel and Boehmer, 2006). The neural circuitry underlying cataplexy is not known, hampering development of treatments that could block such attacks. Narcolepsy is now considered to be a neurodegenerative disorder resulting from the loss of neurons containing the neuropeptide orexin, also named hypocretin (Peyron et al., 2000; Thannickal et al., 2000). Consistent with the neuronal loss, narcoleptic patients have low to neg-

Received Nov. 19, 2010; revised Feb. 16, 2011; accepted Feb. 22, 2011.

Author contributions: M.L., C.B.-C., and P.J.S. designed research; M.L., C.B.-C., R.K., S.B., and D.P. performed research; T.S., M.Y., and A.N.v.d.P. contributed unpublished reagents/analytic tools; M.L., C.B.-C., R.K., D.G., and P.J.S. analyzed data; M.L., C.B.-C., and P.J.S. wrote the paper.

The authors declare no competing financial interests.

*M.L. and C.B.-C. contributed equally to this work.

This work was supported by National Institutes of Health Grants HL091363, MH055772, NS030140, NS052287, NS48476, NS41454, and DK084052, Medical Research Service of the Department of Veterans Affairs (P.J.S.), and a J. Christian Gillin Research Grant from the Sleep Research Foundation (C.B.-C.).

Correspondence should be addressed to either of the following: Dr. Carlos Blanco-Centurion, Medical University of South Carolina, Department of Psychiatry and Behavioral Science, 100 Doughty Street, Room PH141G, Charleston, SC 29425, E-mail: blancoce@musc.edu; or Dr. Priyattam J. Shiromani, Ralph H. Johnson Veterans Affairs Medical Center, Medical University of South Carolina, Department of Psychiatry and Behavioral Science, 114 Doughty Street, MSC 404, Charleston, SC 29425, E-mail: shiroman@musc.edu.

M. Liu, R. Konadhode, and D. Pelluru's present address: Medical University of South Carolina, Department of Psychiatry and Behavioral Science, 114 Doughty Street, MSC 404, Charleston, SC 29425.

DOI:10.1523/JNEUROSCI.6069-10.2011

Copyright $\odot 2011$ the authors $\quad 0270-6474 / 11 / 316028-13 \$ 15.00 / 0$ ligible levels of orexin-A in the CSF (Nishino et al., 2000). Two other peptides, dynorphin and NARP (neuronal activity-related pentraxin), that colocalize with orexin are also absent in postmortem tissue from human narcoleptics (Blouin et al., 2005; Crocker et al., 2005), indicating loss of the orexin neurons rather than reduction of the peptide.

The orexin neurons are distributed in the perifornical and posterior hypothalamus from where they project to the entire brain and spinal cord (de Lecea et al., 1998; Peyron et al., 1998; Sakurai et al., 1998). In narcolepsy, these neurons have already died. Therefore, it is important to identify surrogate neurons in the brain that could alleviate the dysfunction. In the present study, a recombinant adenoassociated viral (rAAV) vector was used to deliver the gene for mouse prepro-orexin (rAAV-orexin) or the reporter gene, green fluorescent protein (rAAV-GFP), into specific brain regions of orexin-ataxin-3 transgenic mice (Hara et al., 2001), a reliable mouse model of narcolepsy that also exhibits unambiguous bouts of cataplexy. AAV has the advantage of facilitating long-term gene expression in rodents and humans without complications associated with viral vectors that integrate into the host genome and potentially initiate tumor formation $(\mathrm{Mu}-$ eller and Flotte, 2008). Another rAAV vector was created to specifically express orexin only in melanin-concentrating hormone $(\mathrm{MCH})$-containing neurons (rAAV-MCH-orexin). These served as possible substitutes for the orexin neurons because they are located in the same regions of the hypothalamus, and project to many of the same regions of the CNS (Bittencourt et al., 1992). The results indicate that the $\mathrm{MCH}$ neurons that synthesized 
orexin did not block cataplexy. In contrast, insertion of the orexin gene into the zona incerta blocked cataplexy, and without adversely affecting overall levels of sleep and wake. This indicates that neurons outside of the perifornical area could be a potential target for orexin gene replacement in the treatment for narcolepsy.

\section{Materials and Methods}

Ethics statement. All manipulations done to the mice adhered to the National Institutes of Health Guide for the Care and Use of Laboratory Animals and were approved by the local committee competent on these matters.

Construction of rAAV vector. Orexin cDNA (393 bp from the laboratory of M. Yanagisawa) was used as a template to get the AU1-Orexin fragment by PCR with following primers: $5^{\prime}$-AAATATGCGGCCGCGCCACCATGGATACGTATCGCTACATATC-3' and 5'-GACCGGCTCGAGTCAGACTCCGGACCCTC-3' . AU1, a small tag peptide with only 6 aa, is used widely as a marker protein in vector construction since it can be easily detected by immunostaining methods. However, it is too small to affect the function of the main protein. AU1 immunostaining was used to distinguish recombinant orexin from endogenous orexin. After cutting by XhoI and NotI, this PCR fragment was inserted into plasmid (p) pAAV-MCS (MCS = multiclonal site; from the laboratory of Dr. Jeng-Shin Lee, Harvard Gene Therapy Initiative, Harvard University, Boston, MA) to form pAAV-MCSAU1-Orexin. Similar method was used to create pAAV-MCS-GFP by inserting GFP CDNA into pAAV-MCS.

To create vector expressing orexin only in $\mathrm{MCH}$ neurons, the cytomegalovirus promoter fragment between BsrGI and Bbsl sites in pAAVMCS-AU1-Orexin and pAAV-MCS-GFP was replaced by mouse MCH promoter (400 bp; from the laboratory of A. N. van den Pol) to form pAAV-MCS-MCHp-AU1-Orexin and pAAV-MCS-MCHp-GFP.

Vector packaging and titering were done by the Harvard Gene Therapy Initiative Laboratory. Briefly, the tripartite transfection (AAV-rep/cap expression plasmid, adenovirus miniplasmid, and our vector plasmid) was done in 293A cells and virus was purified by iodixanol gradient followed by $Q$ Sepharose column chromatography. Purified virus was dialyzed against PBS, concentrated by Millipore spin column, and titered by dot blot hybridization. The titers of all vectors were between 2.7 and $3.0 \times 10^{13}$ genomic copies $/ \mathrm{ml}$.

Delivery of vector. The experimental (rAAV-orexin or rAAV-MCHorexin) and control (rAAV-GFP) vectors were delivered in a volume of $0.75 \mu \mathrm{l}$ each side with a Hamilton syringe $(2.0 \mu \mathrm{l})$ coupled to a stainlesssteel injector cannula (33G; Plastics One). Injection was done gradually over $15 \mathrm{~min}$. After the microinjection, the injector needle was left in place for $10 \mathrm{~min}$ and then withdrawn slowly.

CSF orexin-A levels assayed with ELISA. CSF was collected from the cisterna magna of wild-type (WT) mice (C57BL/6J) and separate groups of orexin-ataxin-3 mice transfected with control and orexin gene rAAV vectors (rAAV-orexin, rAAV-GFP, or rAAV-MCH-orexin) following a modified technique previously published (Fischer et al., 2006) and stored at $-80^{\circ} \mathrm{C}$. In each of the nine groups, mice were ranked based on the number of orexin-immunoreactive (orexin-ir)-positive neurons. The CSF from the top five ranked mice for each group was pooled to obtain the required $50 \mu \mathrm{l}$ of CSF for the assay (10 $\mu \mathrm{l}$ from each mouse). It was necessary to pool the CSF since each mouse yielded only approximately $\sim 10-15 \mu \mathrm{l}$ of CSF. The concentration of orexin-A in the CSF was estimated using fluorescent ELISA according to the manufacturer's instructions (FEK-003-30; range, 0-10 ng/ml; sensitivity, 25.4 pg/ml; Phoenix Pharmaceuticals).

To confirm the levels seen in the orexin-ataxin-3 mice were in the range of normal mice, CSF was collected from two separate groups of WT mice. To provide additional reference points, CSF was collected from the cisterna magna of Sprague Dawley rats $(300 \mathrm{~g})$ at ZT 5 ( $5 \mathrm{~h}$ after lights on). In rats, $\sim 80-100 \mu \mathrm{l}$ of CSF could be extracted from each rat, and, as such, the assay was performed on individual rats. CSF was collected from rats and mice under deep anesthesia ( $2 \%$ isoflurane). For the duplicate WT mice samples, there was concordance between the two samples, and the two data points were averaged.

Mice and sleep recording electrodes. Orexin-ataxin-3 transgenic mice were bred in our facility, and mice carrying the ataxin gene were identi-
Table 1. Tally of orexin-A-ir neurons in WT and orexin-ataxin-3 mice

\begin{tabular}{llc}
\hline & Group & $\begin{array}{l}\text { Average no. of orexin-ir } \\
\text { neurons }\end{array}$ \\
\hline 1 & No rAAV $(n=7)$ & $0.76(0.47)^{*}$ \\
2 & rAAV-GFP $(n=10)$ & $0.50(0.21)^{*}$ \\
3 & rAAV-MCH-orexin $(30 \%$ of MCH neurons) $(n=9)$ & $31.08(5.53)^{*}$ \\
4 & Dilute rAAV-orexin in LH $(n=6)$ & $55.56(8.3)^{* *}$ \\
5 & rAAV-MCH-orexin $(65 \%$ of MCH neurons) $(n=7)$ & $94.76(11.55)^{* * *}$ \\
6 & rAAV-orexin in striatum $(n=9)$ & $115.45(17.57)^{* * * *}$ \\
7 & rAAV-orexin in ZI $(n=8)$ & $138.31(12.24)^{* * * *}$ \\
8 & rAAV-orexin in LH $(n=11)$ & $179.4(25.75)^{* * * * *}$ \\
9 & WT $(n=6)$ & $121.81(8.71)$ \\
\hline Allorexin-A-irneurons were counted in both hemispheres. An average count per section was determined for each
\end{tabular}

All orexin-A-ir neurons were counted in both hemispheres. An average count per section was determined for each mouse. The table summarizes the group average ( \pm SEM).

One-way ANOVA $\left(F_{(8,72)}=20.07 ; p<0.001\right)$ determined significant difference between groups. *Versus groups $5-9$; **versus groups $6-9(p<0.04)$; ***versus groups $1,2,3,8(p<0.03)$; ****ersus $1,2,3,4,8(p<0.03)$; *****versus all groups $(p<0.05)$.

fied using PCR of tail snips. The mice have been backcrossed for many generations on a C57BL/6J line. The mice (6-9 months of age; 20-35 g) were implanted under anesthesia (continuous isoflurane at $2 \%$ ) with electrodes to record the electroencephalogram (EEG) (Plastics One; part 81E3639616XE) and electromyogram (EMG) (Plastics One; part 81E36376-20E) as described previously (Shiromani et al., 2004). Four stainless-steel screw electrodes were positioned in the skull to sit on the surface of the cortex and were used to record the EEG. Two cortical screw electrodes (one frontal cortex and the second in the contralateral parietal cortex) recorded the EEG and two flexible multistranded wires in the nuchal muscles recorded the muscle activity. The electrodes were bundled and secured onto the skull using dental cement. WT mice of the same age and background strain $(\mathrm{C} 57 \mathrm{BL} / 6 \mathrm{~J})$ as the orexin-ataxin-3 mice were also implanted with sleep recording electrodes.

Sleep experiment protocol. A week after the surgery, the animals were connected to lightweight recording cables and allowed 2 weeks of adaptation. On day 21 , a $48 \mathrm{~h}$ baseline sleep recording was made. Thereafter, the mice were anesthetized, CSF was obtained, and then the brains were perfused for histology.

Sleep recording. The EEG was recorded from two contralateral screws (frontal-occipital). The EMG signal was recorded from nuchal muscles. The EEG and EMG signals were amplified via a Grass polygraph and recorded onto the hard disk using an analog-digital board (Kissei Comtec; www.sleepsign.com). The animals were housed singly in Plexiglas cages with food and water available ad libitum. The temperature in the sleep recording room was $25^{\circ} \mathrm{C}$ and a $12 \mathrm{~h}$ light/dark cycle (7:00 A.M. to 7:00 P.M. lights on; 100 lux) was maintained.

Identification of sleep-wake states. The $48 \mathrm{~h}$ EEG, EMG, and video recordings were scored manually on a computer (SleepSign Software; Kissei Comtec; www.sleepsign.com) in $12 \mathrm{~s}$ epochs for wake, non-rapid eye movement (non-REM) sleep, REM sleep, sleep attacks, and cataplexy by staff blind to the type of vector administered to the animal. Wakefulness was identified by the presence of desynchronized EEG and high EMG activity. Non-REM sleep consisted of high-amplitude slow waves together with a low EMG tone relative to waking. REM sleep was identified by the presence of regular EEG theta activity coupled with low EMG relative to slow wave sleep. Identification of cataplexy and sleep attacks is given below. The amount of time spent in wakefulness, non-REM sleep, REM sleep, cataplexy, and sleep attacks was determined for each hour. After the EEG data were scored, the code was broken to reveal the identity of each mouse.

Identification of cataplexy. The EEG and EMG recordings were examined for signs of sudden loss of muscle tone when the mice were awake. Previously, in the orexin-ataxin-3 mice, such episodes were referred to as "behavioral arrests" because the mice abruptly stop moving and lost muscle tone while engaged in behavioral activity (Chemelli et al., 1999). In rats and mice with loss of the orexin or of the orexin neurons, such behavioral incidences are clearly evident on the EEG/EMG and on the video recordings. In the present study, these episodes are referred to as cataplexy. The behavior of all of the orexin-ataxin-3 and WT mice was 

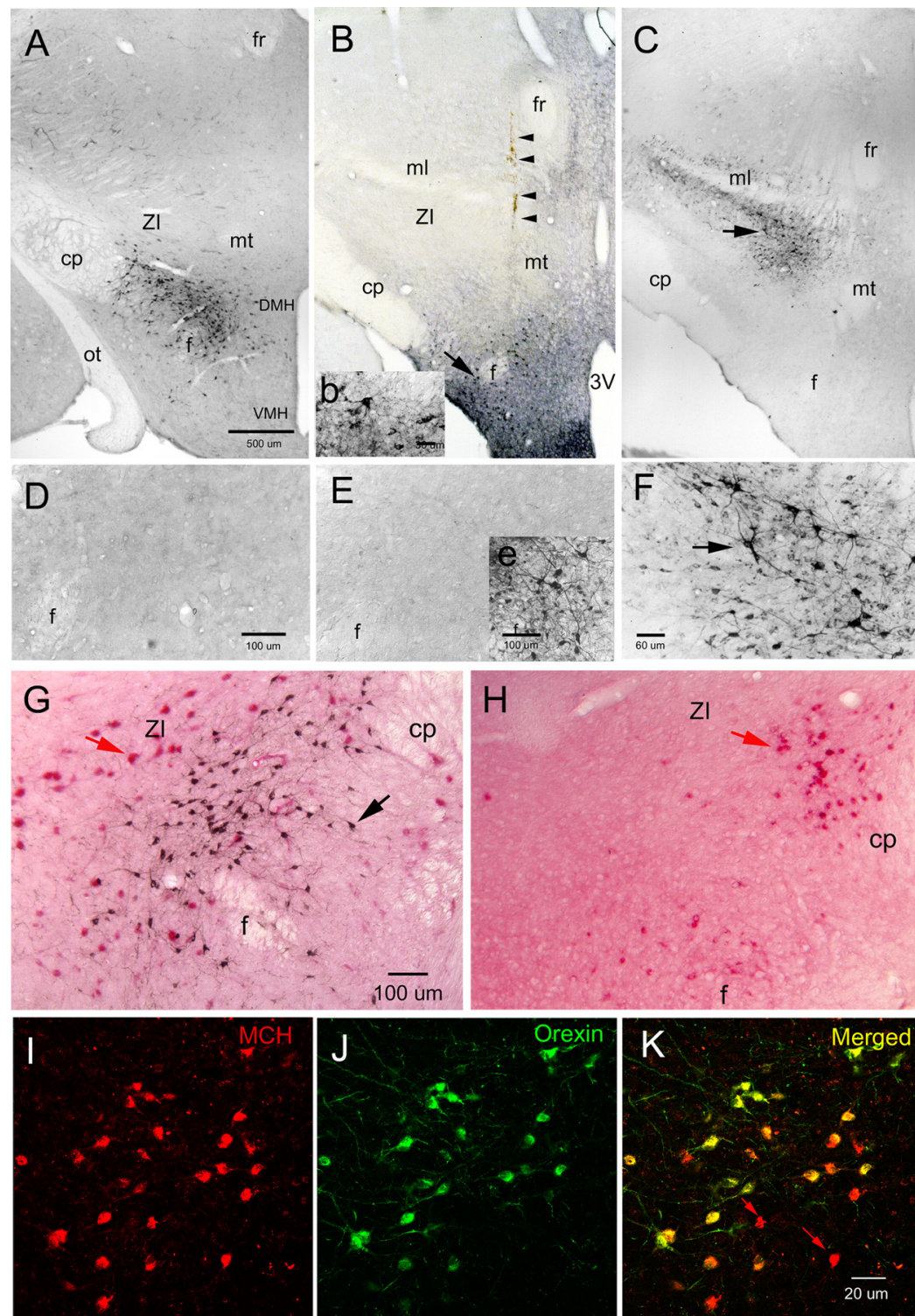

\section{$1 \overline{100 \mathrm{um}}$}
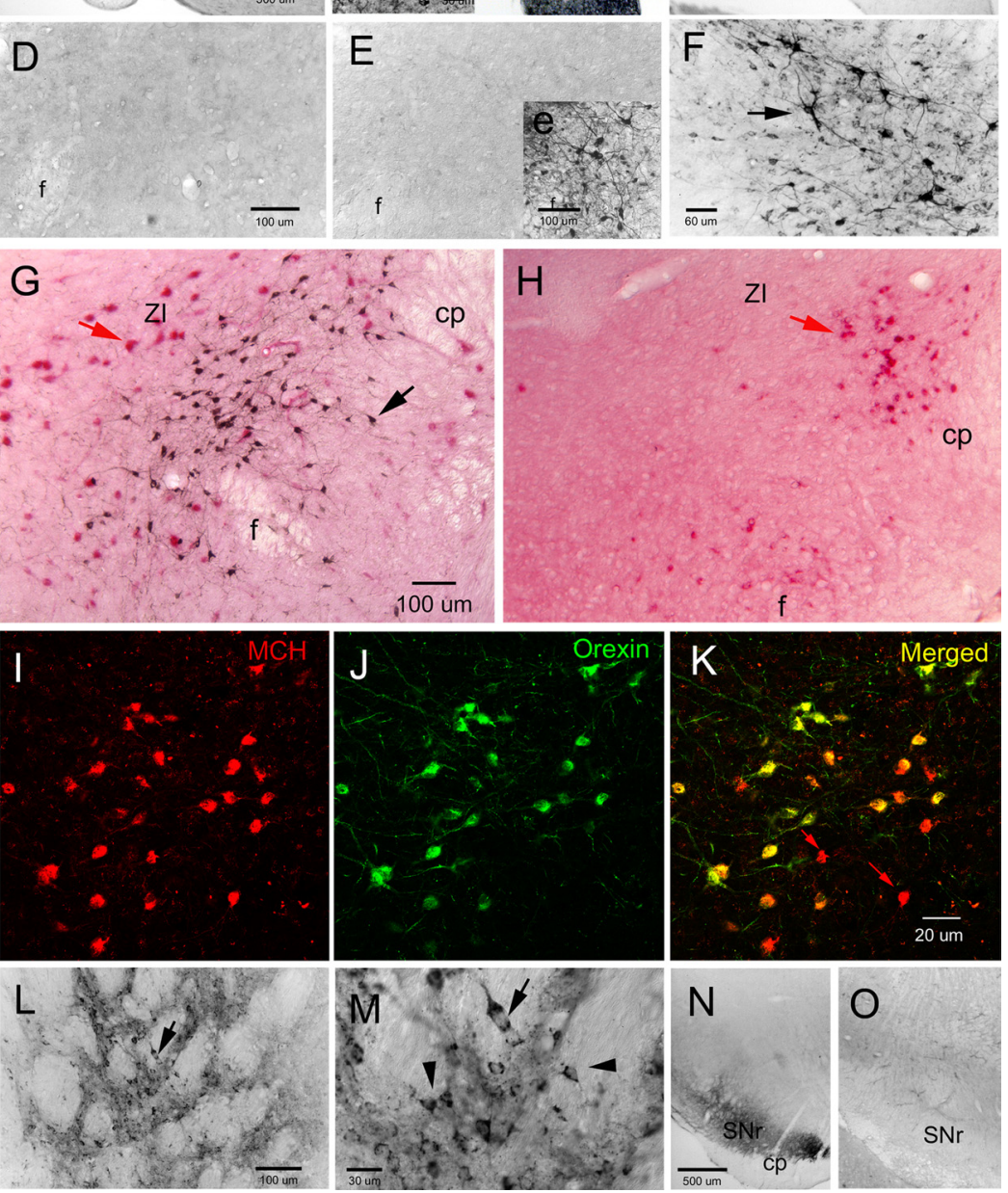

Figure 1. Orexin-A-immunoreactive somata in wild-type $\mathrm{C} 57 \mathrm{BL} / 6 \mathrm{~J}(\boldsymbol{A}, \boldsymbol{G})$ and orexin-ataxin-3 transgenic mice. Photomicrographs represent coronal sections of areas of the mouse brain processed for visualization of orexin-A immunoreactivity. In WT mice, the orexin neurons are localized around the fornix in the posterior hypothalamus $(\boldsymbol{A})$. A higher magnification view of the orexin neurons (black precipitate from the immunohistochemical process) in WT mice is shown in $\mathbf{G}$. In the orexin-ataxin-3 mice, there was a selective degeneration (99.4\%) of the orexin neurons because of the genetically targeted accumulation of the polyglutamine cytotoxicity in these neurons $(\boldsymbol{H})$. However, other neurons including neurons containing melanin-concentrating hormone (red precipitate from alkaline phosphatase immunohistochemical process in $\boldsymbol{G}$ and $\boldsymbol{H}$ ) are still present in the orexin-ataxin-3 mice $(\boldsymbol{H})$ and could serve as surrogate neurons expressing orexin. In the present study, a rAAV vector transferred the gene for mouse prepro-orexin into specific brain regions in the orexin-ataxin-3 mouse. In the transgenic mice given no-rAAV (D) or given the control reporter gene green fluorescent protein (rAAV-GFP) $(\boldsymbol{E})$, there were no orexin neurons present. In the latter group, GFPimmunoreactive neurons were evident at the injection site in the perifornical region indicating successful GFP gene transfer (inset $\boldsymbol{e})$. In two groups of orexin-ataxin-3 mice, rAAV-orexin was delivered to the posterior hypothalamus and the two groups were formed based on the location of the neurons expressing orexin: a ventral group ( $\boldsymbol{B}$, inset $\boldsymbol{b})$ in which the orexin neurons were diffusely present around the perifornical region and representative of the distribution of orexin neurons in WT mice $(\boldsymbol{A})$, and a dorsal group $(\boldsymbol{C})$ in which the orexin neurons are not located in WT mice but rAAV-orexin gene delivery produced the orexin- $A$-ir neurons in and around the zona incerta. In $\boldsymbol{B}$, the arrow points to orexin neurons around the fornix (higher magnification is inset $\boldsymbol{b}$ ), and the arrowheads indicate the injection needle tract. In $\boldsymbol{C}$, the arrow identifies the orexin neurons clustered in the $Z \mathbf{Z l}$. $\boldsymbol{F}$ represents higher magnification of neurons identified by the arrow in $\mathbf{C}$. Since the MCH neurons are present in the orexin-ataxin-3 mice, two videotaped and cataplexy was verified using both video and EEG/EMG recordings (Scammell et al., 2009). Strict criteria were used to identify cataplexy: such episodes had to occur when the mouse was awake ( $\geq 36 \mathrm{~s}$; three epochs since we score sleep-wake states in $12 \mathrm{~s}$ epochs) and engaged in an active behavior such as walking, running, grooming, eating, or drinking; the episode had to last at least $12 \mathrm{~s}$ (one epoch since we score sleep-wake states in $12 \mathrm{~s}$ epochs); during the episode, theta activity had to be present, and delta activity diminished; and there was loss of muscle tone (see Fig. 5). The number and duration of each of these episodes during the $12 \mathrm{~h}$ day and night periods were determined.

Identification of sleep attacks. In these attacks, the mice entered briefly into non-REM sleep during active behaviors such as grooming, eating, or drinking. These episodes were separate and distinct from cataplexy since the mice did not lose muscle tone and there was a mixture of delta and theta activity in the EEG, in contrast to cataplexy when theta activity dominated (see Fig. 5). Moreover, these attacks did not occur when the mouse was running or walking.

Analysis of the EEG frequency (fast Fourier transform). The spectrum of the EEG frequencies from 0 to $60 \mathrm{~Hz}$ during each $12 \mathrm{~s}$ epoch was automatically quantified by the SleepSign software and placed in $1.0 \mathrm{~Hz}$ bins. This spectrum was determined for each sleep state (wake, non-REM sleep, and REM sleep) for each animal during the $12 \mathrm{~h}$ day and night periods. An overall spectrum of frequencies during each $12 \mathrm{~s}$ epoch, regardless of sleep state, was also determined for each animal during the $12 \mathrm{~h}$ day and night periods. Because there is enormous variability in the amplitude of the EEG between animals, the fast Fourier transformation (FFT) data were normalized for each animal and the spectrum represents the ratio of the sleep state specific frequency divided by the overall frequency during each $12 \mathrm{~h}$ period.

groups of orexin-ataxin-3 mice were given rAAV-MCH-orexin that expressed orexin under the control of the MCH promoter. I- $K$ represent confocal laser-scanned images of the $\mathrm{MCH}$ neurons $(\boldsymbol{I})$ that also contain orexin $(\boldsymbol{J}, \boldsymbol{K})$ in orexin-ataxin-3 mice. The virus did not infect all of the MCH neurons as some (identified by red arrows in $\boldsymbol{K}$ ) $\mathrm{MCH}$ neurons did not express orexin. To further define specificity of the effect, in another group of transgenic mice, rAAV-orexin was delivered to the striatum (L). $M$ is a higher magnification of neurons identified by arrow in $L$. $\ln M$, the arrowheads identify small neurons relative to the larger neuron (arrow) that express orexin. Orexin gene delivery to the striatum resulted in intense orexin fibers in the substantia nigra reticulata $(\boldsymbol{N})$. In WT mice, such fibers are not present (0). The scale bar in $\boldsymbol{A}$ applies to $\boldsymbol{B}$ and $\boldsymbol{C}$, the scale bar in $\boldsymbol{D}$ applies to $\boldsymbol{E}$, the scale bar in $\boldsymbol{G}$ applies to $\boldsymbol{H}$, the scale bar in $\boldsymbol{K}$ applies to $\boldsymbol{I}$ and $\boldsymbol{J}$, and the scale bar in $\boldsymbol{N}$ applies to $\boldsymbol{O}$. Abbreviations: $3 \mathrm{~V}$, Third ventricle; $\mathrm{cp}$, cerebral peduncle; $\mathrm{DMH}$, dorsomedial hypothalamus; f, fornix; fr, fasciculus retroflexus; $\mathrm{ml}$, medial lemniscus; mt, mammillothalamic tract; ot, optic tract; SNr, substantia nigra reticulata; VMH, ventral medial hypothalamus; Zl, zona incerta. 


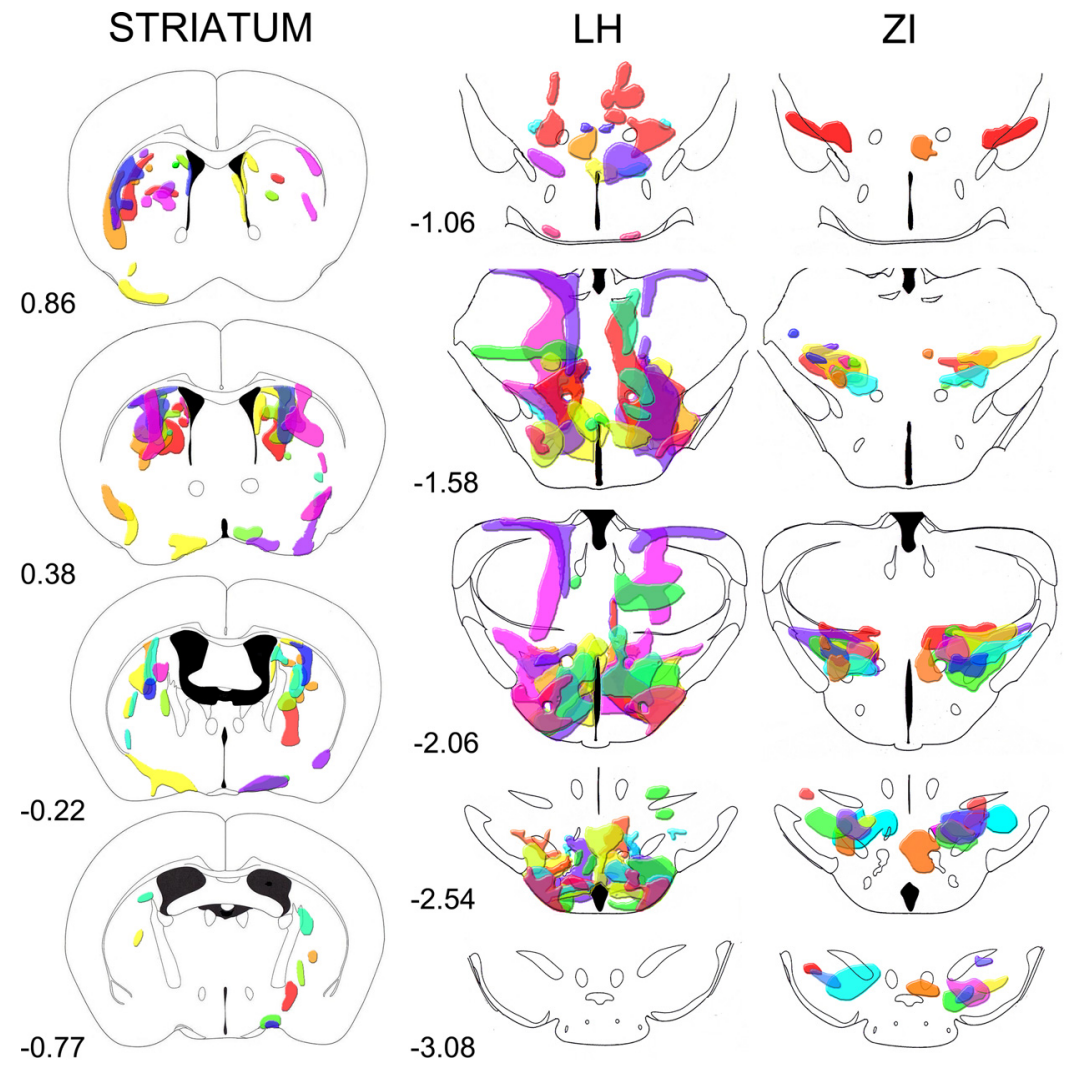

Figure 2. Schematicrepresentation of the distribution of orexin- $A$-irneurons in the striatum, $\mathrm{LH}$, and Zl groups. The drawings represent coronal sections of the brain regions where the orexin-A-ir neurons were present. Each color shows the distribution in one mouse, and independent mice were used in each group. The numbers below each schematic drawing represent the distance relative to bregma.
Tally of orexin- and MCH-immunoreactive cells. The mice were deeply anesthetized with Nembutal; the brains were perfused transcardially with $0.9 \%$ saline $(5 \mathrm{ml})$ followed by $10 \%$ buffered formalin in $0.1 \mathrm{M}$ PBS $(20 \mathrm{ml})$. The brains were placed in $30 \%$ sucrose $(0.1 \mathrm{M}$ PBS) and allowed to equilibrate. The tissue was cut on a cryostat (40- $\mu \mathrm{m}$-thick sections) and onein-four series of sections were processed for visualization of orexin-A-ir neurons. The tissue was incubated overnight at room temperature in the primary antibody [goat anti-orexin-A antibody (Santa Cruz; 1:10,000 for bright field or 1:1000 for immunofluorescence)] and visualized either using $\mathrm{ABC}-\mathrm{DAB}$-nickel staining (Vector Laboratories) or Alexa Fluor 488conjugated donkey anti-goat IgG ( $2 \mathrm{~h}$ incubation; 1:500; Invitrogen). For $\mathrm{MCH}$ staining, sections were also incubated overnight at room temperature with rabbit anti-MCH (1:10,000; Phoenix Pharmaceuticals) and then visualized using alkaline phosphatase (Vector Laboratories). Immunofluorescence $\mathrm{MCH}$ staining was done using Alexa Fluor 568-conjugated donkey anti-rabbit ( $2 \mathrm{~h}$ incubation; 1:500; Invitrogen). The labeled sections were then mounted onto gelatin-coated slides and coverslipped using bright-field (Richard-Allan) or fluorescence mounting medium (Dako). For brightfield imaging, every fourth section in the series containing orexin-ir-positive cells was digitized at high resolution $(40 \times$ tiled image), the orexin-A-ir somata were manually tagged and later counted off-line using MCID software. The tally of neurons containing $\mathrm{MCH}$ or $\mathrm{MCH}$

Table 2. Relative density of orexin-A-immunoreactive fibers in WT and orexin-ataxin-3 mice given the orexin gene transfer

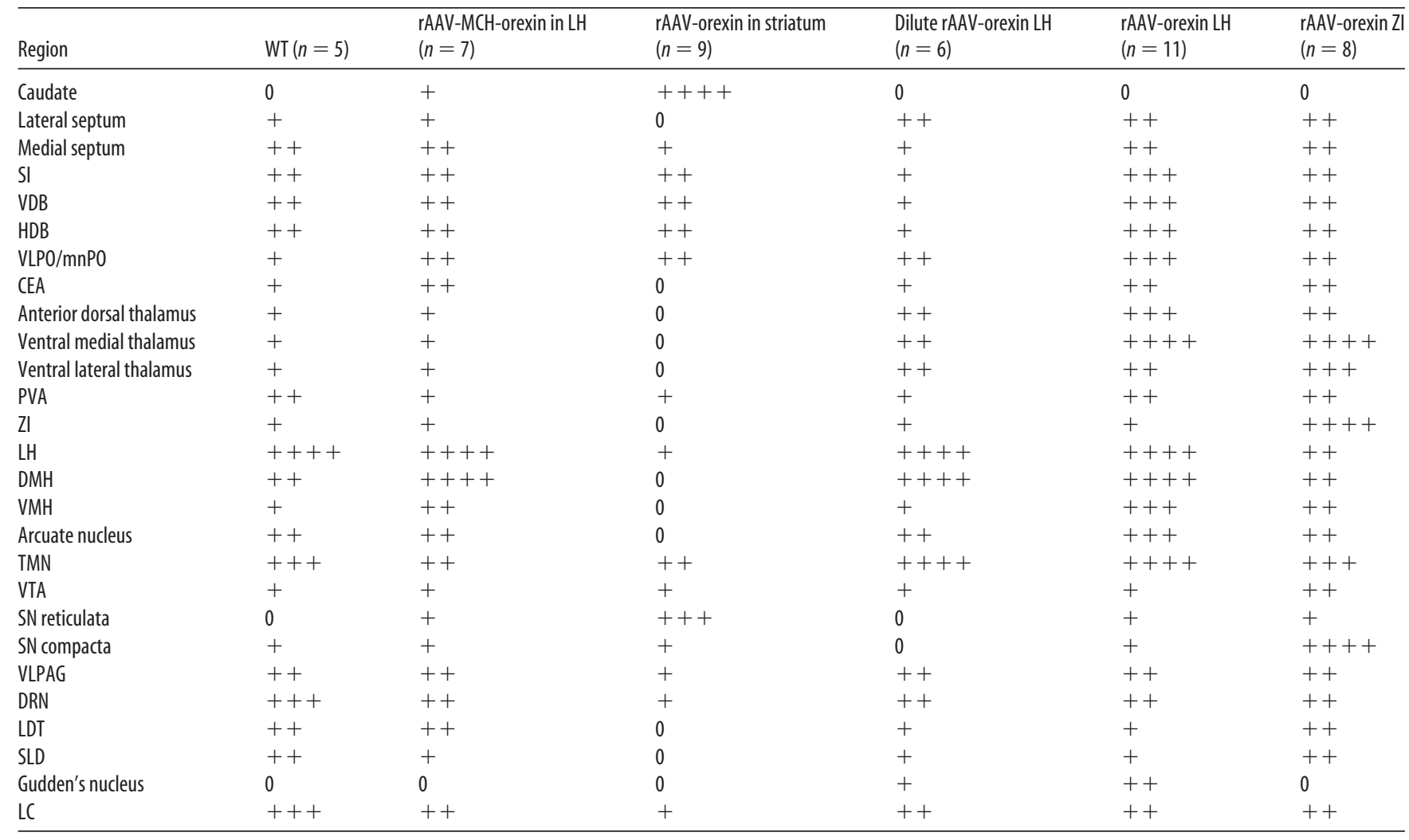


plus orexin-A were done in the same way as described above except different tags were used for $\mathrm{MCH}$ and orexin. The tally was derived from seven to eight coronal sections (from one-in-four series) that contained the highest density of orexin-A-labeled cells. The tally represents the average number of labeled neurons for each mouse. For every mouse transfected with rAAV-MCH-orexin, orexin-A-ir was confirmed using a Zeiss LMS 710-confocal 3 microscope (Carl Zeiss). The images for each section were scanned in a $Z$-stack mode $(1 \mu \mathrm{m}$ interval). The colocalization of $\mathrm{MCH}$ and orexin was confirmed by orthogonal viewing of the cell ( $x-y, x-z$, and $y-z$ directions).

Statistical analysis. One-way ANOVA with appropriate post hoc tests was used. Statistical significance was evaluated at the $p<0.05$ level (two-tailed).

\section{Results}

Tally, distribution, and projections of rAAV-induced orexin neurons

Together, there were nine groups in the study including a WT mice group that did not receive rAAV (Table 1). Orexin-A-ir neurons were counted in WT mice and served as reference for transgenic mice receiving rAAV. In WT mice, the orexinA-ir neurons are located specifically around the perifornical region of the posterior hypothalamus (Fig. 1A,G). The three vectors (rAAV-orexin, rAAV-GFP, or rAAV-MCH-orexin) were delivered directly into specific brain regions of the orexin-ataxin-3 mice and 3 weeks later sleep-wake behavior, tally of orexin neurons, and levels of orexin in the CSF were assessed. In the orexin-ataxin-3 mice, the accumulation of polyglutamine cytoxicity kills the orexin neurons by the time the mice are 3 weeks of age (Hara et al., 2001). In the present study, to insure a more complete loss of the orexin neurons, 6- to 9-month-old mice were used.

In orexin-ataxin- 3 mice not given the gene (no-rAAV; $n=7$ ) (Fig. $1 D$ ) or given the reporter gene (rAAV-GFP; $n=10$ ) (Fig. $1 E$ ), there was an almost complete (99.4\%) loss of orexin neurons (Table $1)$. In these two groups of mice, there were a few vestigial orexin neurons but these appeared faded and lacked any processes.

Orexin-ataxin-3 mice receiving $\mathrm{rAAV}$ were divided into groups based on the distribution of orexin-A neurons. Two groups were formed in mice receiving rAAV-orexin in the posterior hypothalamus (Fig. $1 B, C$ ). In one group, referred to as the lateral hypothalamus ( $\mathrm{LH})$ group

(Fig. $1 B$ ), the orexin-A-ir neurons were localized mostly in the perifornical region, but also in adjacent regions such as the dorsomedial hypothalamus, ventromedial hypothalamus, and the
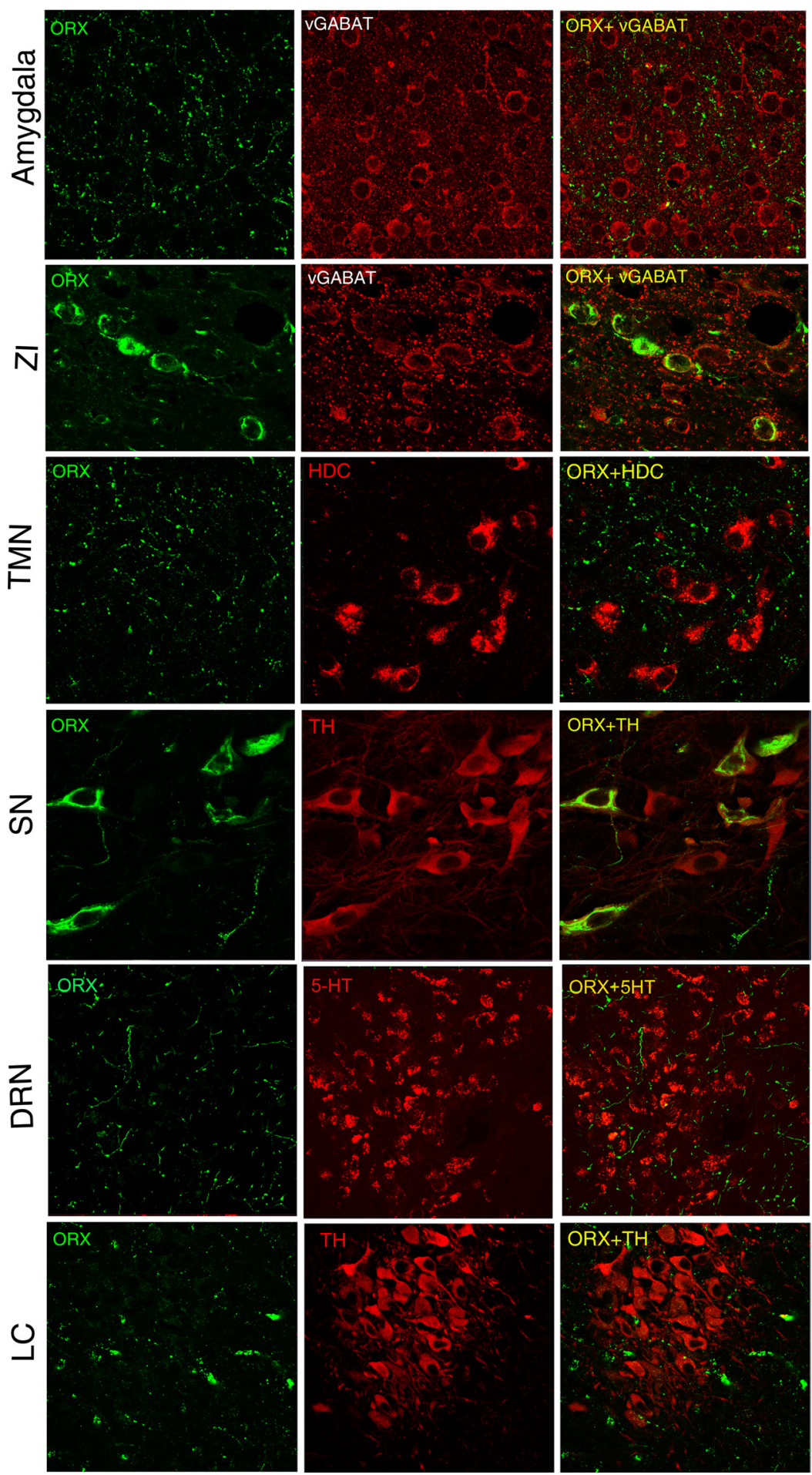

Figure 3. Orexin-A-ir varicosities in various brain regions after orexin gene transfer into the zona incerta. The first column of photomicrographs depicts orexin-A-ir fibers in various brain regions and orexin somata in the zona incerta and substantia nigra (SN). The second column identifies specific phenotypes of neurons and the third column depicts the merged image. In the Zl, the orexin gene is expressed in putative GABA neurons [identified by vesicular GABA transporter (VGABAT)] and in the tyrosine hydroxylase (TH) neurons of the substantia nigra (SN). Orexin-A-ir fibers are seen in limbic areas such as the amygdala, but also in arousal regions such as the TMN, DRN, and LC. Abbreviations:5-HT, 5-Hydroxytryptamine; DRN, dorsal raphe nucleus; HDC, histidine decarboxylase; $\mathrm{LC}$, locus ceruleus; ORX, orexin-A; SN, substantia nigra; TMN, tuberomammillary nucleus; TH, tyrosine hydroxylase; $\mathrm{VGABAT}$, vesicular GABA transporter; Zl, zona incerta.

tuberomammillary nucleus (TMN). In this group, in some mice, orexin-A-ir neurons were also present dorsally in the thalamus, most likely from the unintended leakage from the injection cannula. In the other group (Fig. 1C), virtually all of the neurons 


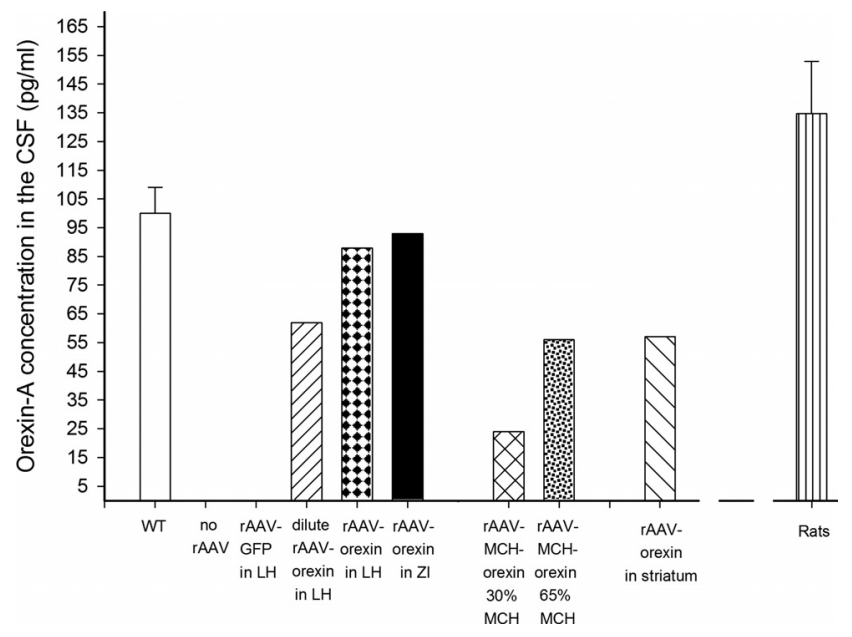

Figure 4. Levels of orexin-A in the CSF of mice and rats assessed by ELISA. Concentration of orexin- $A$ (in picograms per milliliter) in the CSF of $(57 \mathrm{BL} / 6 \mathrm{~J}$ mice and Sprague Dawley rats assessed by ELISA. The levels of orexin-A in WT C57BL/6J mice were assessed at the same circadian time points as in the orexin-ataxin-3 mice. The levels in the Sprague Dawley rats ( $n=$ 5) serve to verify the utility of the assay to detect orexin-A in the CSF. Orexin-ataxin-3 mice in the no-rAAV group or administered the control reporter gene (rAAV-GFP) had levels of orexin-A that were below detection limits. However, in the other groups, orexin-A levels approached levels in WT mice. The CSF was collected from the cisterna magna of mice and rats and stored at $-80^{\circ} \mathrm{C}$. A maximum of $\sim 10-15 \mu$ l of CSF could be acquired from each mouse. Therefore, CSF samples from five mice (ranks based on number of orexin-A-ir neurons) were pooled to yield the $50 \mu \mathrm{l}$ required for the assay. WT mice represent average CSF from two separate groups. In rats, CSF from individual rats $(n=5)$ was used in the assay. Error bars indicate SEM.

were concentrated more dorsally and slightly caudal to the perifornical region mostly in the zona incerta (ZI), with a few neurons in the ventral and lateral thalamus and the substantia nigra. In this group (ZI group), few if any orexin-A-ir neurons were present in the perifornical area, LH, or TMN. Thus, in the ZI group, the orexin neurons were distributed dorsal to the perifornical region, which allowed us to determine whether subthalamic regions might be recruited to block narcoleptic behavior. In this group, the number of transfected orexin neurons was not different from WT (Table 1). Distribution of orexin-A-ir neurons in these two groups is schematized in Figure 2.

In the LH group, the number of transfected orexin-A-ir neurons was significantly more than WT $(p<0.05)$ (Table 1$)$. Another group of orexin-ataxin-3 mice were given a 1:10 dilution of rAAVorexin into the LH (dilute rAAV-orexin). In this group, the transfected orexin neurons were also located mostly in the perifornical area, $\mathrm{LH}$, and some in the TMN. In the dilute rAAV-orexin group, there were $45 \%$ as many orexin-A-ir neurons as WT $(p=0.04)$.

Within the ZI and LH, there are numerous neurons that contain melanin-concentrating hormone (Fig. $1 G, H$ ). The rAAVorexin is a nonspecific vector infecting all neurons including the $\mathrm{MCH}$ neurons. In the $\mathrm{LH}$ and $\mathrm{ZI}$ groups, $\mathrm{MCH}$ neurons were infected and coexpressed orexin. To determine whether the virally mediated expression of orexin in the $\mathrm{MCH}$ neuron could decrease cataplexy, orexin expression was limited specifically to the $\mathrm{MCH}$ neurons via an $\mathrm{MCH}$ promoter (rAAV-MCH-orexin) (Fig. $1 I-K$ ). Two groups were formed based on the number of $\mathrm{MCH}$ neurons coexpressing orexin. In the first group, $30 \%$ of the $\mathrm{MCH}$ neurons were orexin-A-ir, whereas in the second group, $65 \%$ of the MCH neurons also contained orexin. Thus, in the latter group, approximately two-thirds of the $\mathrm{MCH}$ neurons also contained orexin (Table 1). The first group had significantly fewer $(25 \%$; $p=0.001$ ) orexin-A-ir neurons as WT mice, whereas the other group had 78\% (not significant vs WT).
To further identify site specificity, the rAAV-orexin was delivered to the striatum (Fig. $1 L, M$ ). In this group were included three mice that had a few orexin-A-ir somata in the basal forebrain and the preoptic area (Fig. 2). In the striatal group of transgenic mice, the number of rAAV-transfected orexin-A-ir neurons was not significantly different from the number of orexin-A-ir neurons in the LH of WT mice (Table 1). Thus, the striatal group had similar numbers of orexin-A-ir neurons compared with the WT mice.

When rAAV-orexin was placed in the LH, ZI, or in two-thirds of the $\mathrm{MCH}$ neurons, numerous orexin-A-ir varicosities were clearly evident in brain regions distal to the gene delivery site. Orexin-A-ir fibers were noted in the diencephalon, septum, basal forebrain, amygdala, locus ceruleus (LC), and dorsal raphe nucleus (DRN) (Table 2). Figure 3 depicts the orexin somata and fibers in the ZI group. In the rAAV-orexin-striatum group, the substantia nigra reticulata was heavily innervated (Fig. $1 N$ ), but orexin processes were not clearly evident in the LC, TMN, DRN (Table 2). Orexin-A-ir somata or fibers were never evident in transgenic mice given control vector (rAAVGFP) or no rAAV.

\section{Orexin-A in the CSF}

Levels of orexin-A in the CSF were assessed to determine the presence of the gene product outside of neurons, thereby indicating release of the peptide. Figure 4 summarizes the concentration of orexin-A in the CSF of mice and rats. CSF was taken from the cisterna magna of Sprague Dawley rats $(n=5)$ to verify the utility of the ELISA method to accurately detect orexin-A levels in the CSF. In the orexin-ataxin-3 mice administered no-rAAV or given the control vector, rAAV-GFP, levels of orexin-A were below the detection limits of the assay. In contrast, in orexin-ataxin-3 mice given the rAAV-orexin gene to the $\mathrm{LH}$ or the $\mathrm{ZI}$, orexin-A was detected in the CSF $24 \mathrm{~d}$ after delivery of the gene. The number of orexin-A-ir neurons in these two groups was quite similar to WT mice and CSF levels of orexin-A were also quite similar to WT. Mice given the dilute rAAV-orexin to the LH had approximately one-half as much orexin-A in the CSF as WT mice. This group also had a little less than one-half as many orexin-A-ir neurons in the LH (Table 1). Orexin gene delivery to the striatum yielded onehalf as much orexin-A in the CSF as WT mice, even though in these mice the number of orexin-A-ir neurons in the $\mathrm{LH}$ was comparable with WT mice. Similarly, in the rAAV-MCH-orexin group in which the number of orexin-A-ir neurons was not significantly different from WT mice, the CSF orexin levels were approximately one-half of those of WT mice. MCH neurons are active primarily during REM sleep (Hassani et al., 2009) and since REM sleep accounts for only $\sim 4 \%$ of all vigilance states in mice, if the amount of orexin detected in the CSF is proportional to the activity of $\mathrm{MCH}$ neurons, this may contribute to reduced CSF orexin-A. Similarly, in the striatum group, orexin was expressed in many of the small spiny interneurons, which might not have yielded enough output to the ventricles.

\section{Effect of gene delivery on cataplexy}

Cataplexy in the orexin-ataxin-3 mice primarily occurs during the night, especially during the first one-half of the night (Hara et al., 2001). In the present study, cataplexy was the first symptom that was assessed since in narcoleptic humans and canines it is an important diagnostic symptom of narcolepsy (Aldrich, 1993; Mignot, 1998). In the orexin-null (Chemelli et al., 1999) and orexin-ataxin-3 (Hara et al., 2001) mice, such episodes occur during periods of waking and can be easily identified because the 


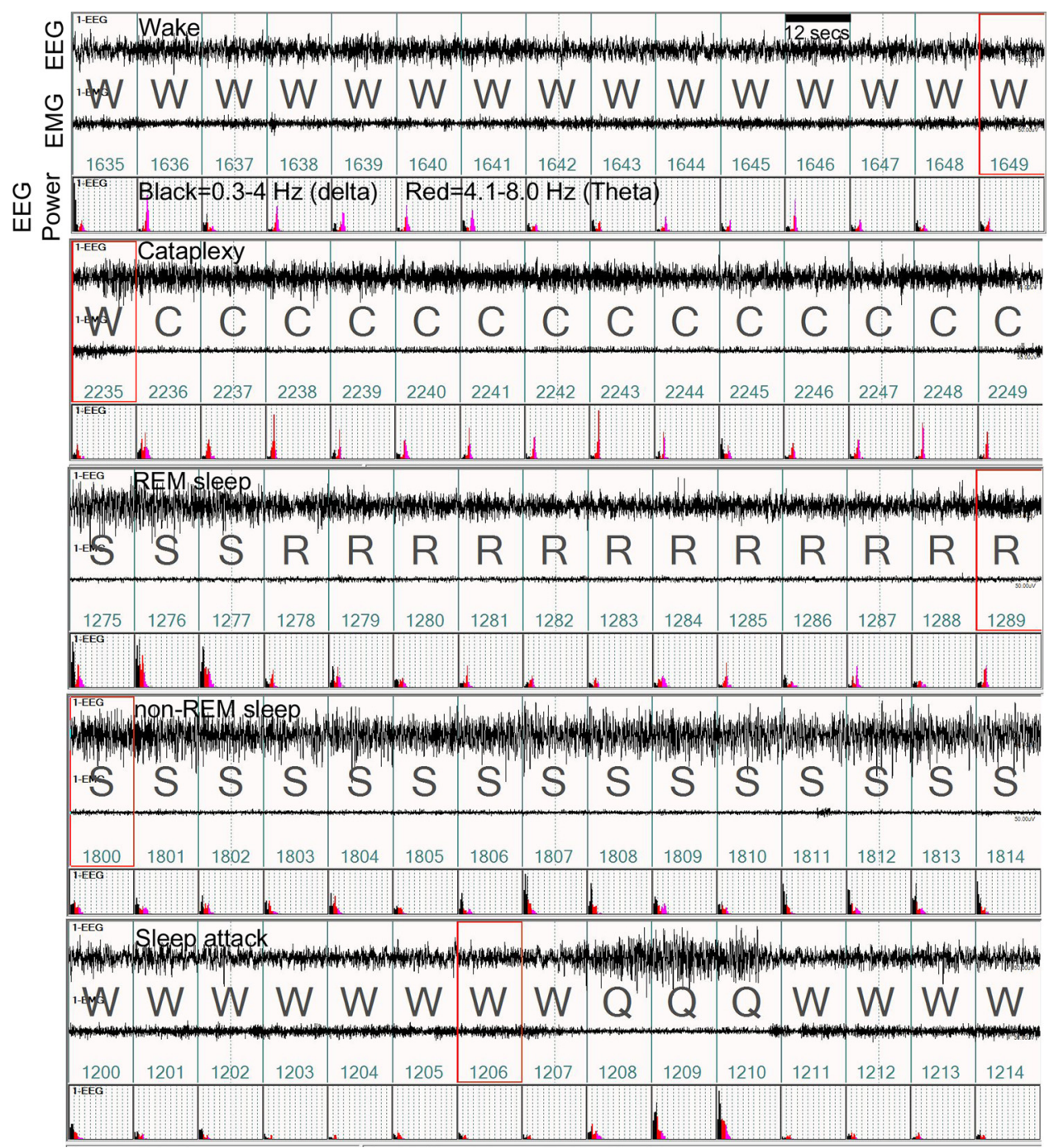

Figure 5. Example of normal and abnormal sleep-wake states in a representative orexin-ataxin-3 mouse given no-rAAV. Each panel consists of a 3 min recording of the EEG, activity of the nuchal muscles (EMG), and power of the EEG in the delta $(0.3-4 \mathrm{~Hz}$; black) and theta bands $(4-8 \mathrm{~Hz}$; red) at night. The sleep-wake state is determined by the relationship of the EEG, EEG power, EMG activity, and simultaneous observation of the behavior via video recording. In the top panel, high EMG activity coupled with low-amplitude EEG, low delta power indicates that the mouse was awake (W). Cataplexy (second panel) is identified by an abrupt loss of EMG tone, postural collapse on video during an active waking, and an increase in theta activity (C). The third panel depicts a normal transition from non-REM to a REM sleep episode in the same mouse. The fourth and fifth panels depict episodes of non-REM sleep and sleep attack. Note that the sleep attack (Q) is brief and occurs while the mouse is engaged in purposeful behavior. It is different from cataplexy in that the mouse is usually upright and there is a mixture of delta/theta power in the EEG. Videotape recordings in all mice verified that the behavior coincided with EEG/EMG indices. Abbreviations: C, Cataplexy; S, non-REM sleep; R, rapid eye movement sleep; $Q$, sleep attack; W, wake. The numbers in green represent the serial epoch labels spanning $12 \mathrm{~s}$ each. The red boxes on epoch 1649,2235, 1289, 1800, and 1206 are visual aids indicating the streaming video file.

mice abruptly stop moving, gradually lose muscle tone, and have high electroencephalographic theta activity (Fig. 5).

Initial data analysis revealed that undiluted orexin gene transfer into the posterior hypothalamus $(n=19)$ significantly reduced percentage cataplexy during both the day $\left(F_{(4,60)}=11.81\right.$; $p<0.001)$ and night $\left(F_{(4,60)}=7.06 ; p<0.001\right)$ compared with no-rAAV, rAAV-GFP, rAAV-orexin in striatum, or rAAV$\mathrm{MCH}$-orexin groups. To gain a better understanding of regional differences in the posterior hypothalamus, the mice receiving the orexin gene transfer into the posterior hypothalamus were divided into two groups, $\mathrm{ZI}$ and $\mathrm{LH}$, based on regional density of orexin-ir neurons.

Mice given the rAAV-orexin gene into the zona incerta $(n=$ $8)$ or the $\mathrm{LH}(n=11)$ had a significant decline in cataplexy during the $12 \mathrm{~h}$ light-off period $\left(F_{(7,66)}=7.39 ; p=0.001\right)$ compared with no-rAAV and GFP groups (Fig. $6 A$ ). In the ZI group, the percentage cataplexy at night ranged from 0 to $1.42 \%$ (range of orexin neurons/section, 89.6-196.4). In the LH group, the percentage cataplexy at night ranged from 0.07 to $0.72 \%$ (range of orexin neurons/section, 83.3-362.1). In the no-rAAV group, the percentage cataplexy at night ranged from 1.31 to $5.22 \%$ (range of orexin neurons/section, $0-2.6$ ). There were no differences between the LH and ZI groups, but both were less than no-rAAV or rAAV-GFP mice, indicating that the ZI can serve as a surrogate site to decrease cataplexy. Mice given the dilute rAAV-orexin $(n=6)$ into the LH had intermediate levels of cataplexy during the first half of the night. However, during the second half of the night, the dilute rAAV-orexin, rAAV-LH, and rAAV-ZI groups had significantly less cataplexy $\left(F_{(4,41)}=7.1 ; p=0.001\right) \mathrm{com}$ pared with the no-rAAV and rAAV-GFP mice groups indicating a dose-response effect. The decrease in cataplexy also occurred during the day cycle in the dilute rAAV-orexin, rAAV-orexin$\mathrm{LH}$, and rAAV-orexin-ZI groups compared with no-rAAV $\left(F_{(7,66)}=4.95 ; p<0.001\right)$. In the rAAV-orexin-LH and ZI 

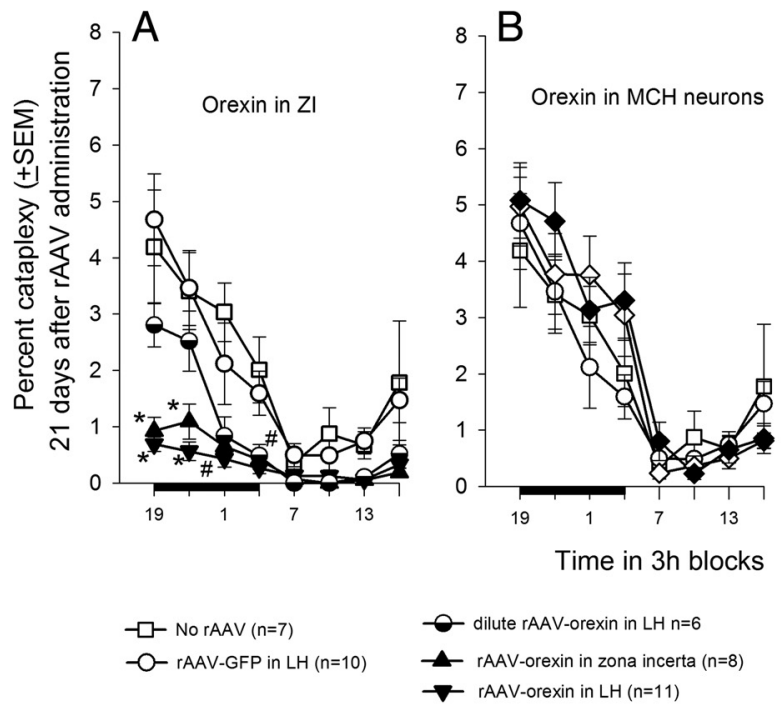

0.001) (Table 5). Thus, placing the orexin gene in the striatum or in two-thirds of the $\mathrm{MCH}$ neurons exacerbated sleep attacks.

\section{Effect on sleep fragmentation}

Orexin gene transfer had no effect on the number or length of wake, non-REM sleep, or REM sleep bouts at night or day compared with the no-rAAV group (Tables 3, 4). Thus, orexin gene transfer did not significantly decrease sleep fragmentation.

\section{Inputs to the zona incerta}

As this is the first study to have identified the zona incerta in regulating an important symptom of narcolepsy, an experiment was conducted to better understand the inputs to this region. In a separate group of orexin-ataxin-3 mice, the retrograde tracer cholera toxin-B (CTb) was microinjected ( $50 \mathrm{nl} ; 2 \%$ ) into the ZI (one hemisphere) of orexin-ataxin-3 mice. One week later, the mice were kept awake for $6 \mathrm{~h}$ and then killed. The brains were processed for immunohistochemical detection of CTb-labeled neurons and for the proto-oncogene c-fos, a marker of groups, there was a significant decrease in the number of bouts of cataplexy during both the day and night (Table 3). In these two groups, the length of the cataplexy bouts at night (Table 4) was also significantly shorter compared with the no-rAAV group ( $\mathrm{Ta}-$ ble 4). Thus, rAAV-orexin gene insertion into the ZI or LH decreased the number and length of the cataplexy bouts at night when cataplexy is usually triggered in the transgenic mice.

Insertion of orexin into the $\mathrm{MCH}$ neurons did not block cataplexy. Even when two-thirds of the MCH neurons were orexin positive, cataplexy levels were not significantly different from the no-rAAV group during both the night and day (Fig. $6 \mathrm{~B}$ ). rAAVorexin applied to the striatum (Fig. 6C) also had no effect on cataplexy even though this group had similar number of orexin neurons as WT mice.

\section{Effect on wake and non-REM}

Figure 7 summarizes the percentage wake, and non-REM sleep levels in all mice in the study. Orexin gene transfer did not significantly change the amount of wakefulness (Fig. 7A-C) or nonREM sleep (Fig. $7 D-F$ ) during day or night periods (Table 5). There was no change in the frequency or amplitude of the EEG either, as determined by FFT analysis of the EEG (Fig. 8).

\section{Effect on REM sleep}

Orexin gene transfer into the ZI or LH groups did not change REM sleep (Fig. 9, Table 5). In the other groups, REM sleep levels were significantly decreased during the day (Fig. 9) compared with no-rAAV.

\section{Effect on sleep attacks}

rAAV-orexin in the LH or ZI did not significantly decrease the time spent in sleep attacks at night (Table 5). However, when the orexin gene was expressed in the striatum or in two-thirds of the $\mathrm{MCH}$ neurons, the percentage of time spent in sleep attacks at night increased compared with no $\operatorname{rAAV}\left(F_{(7,66)}=5.09 ; p<\right.$ neuronal activity (Sagar et al., 1988). Eight mice received the $\mathrm{CTb}$, but only two mice had the tracer restricted to the ZI. In these two mice, numerous retrogradely labeled neurons were identified in the cingulate cortex and amygdala (Fig. 10). The CTb-labeled neurons projecting to the $\mathrm{ZI}$, along with neurons in the contralateral ZI, were also found to contain c-Fos, indicating that these neurons were active during waking.

\section{Discussion}

This study revealed surrogate neurons in the zona incerta that decreased cataplexy. Orexin gene transfer into the striatum or into the $\mathrm{MCH}$ neurons was ineffective, indicating that some populations of neurons in the CNS, even after orexin gene transfer, were still unable to attenuate cataplexy. The ZI has not previously been implicated in narcolepsy, but there is strong evidence that it ameliorates motor tremor in Parkinson's disease (Plaha et al., 2008). Deep brain stimulation of the caudal ZI in patients with Parkinson's disease improves all forms of tremor affecting both the distal and proximal parts of the body (Plaha et al., 2006). Now our results also identify the $\mathrm{ZI}$ as a target of drugs to control muscle paralysis in narcolepsy.

Orexin gene transfer into neurons in the striatum or into the $\mathrm{MCH}$ neurons did not decrease cataplexy even though the number of orexin neurons in these groups was not significantly different than that of WT. Orexin gene transfer into the striatum produced dense orexin innervation of the substantia nigra reticulata, but cataplexy was neither blocked nor was there an increase in wakefulness. Orexin gene transfer was made into the $\mathrm{MCH}$ neurons because the $\mathrm{MCH}$ neurons are located in the same area and, similar to the orexin neurons, project widely throughout the brain (Bittencourt et al., 1992). The brain distribution of the $\mathrm{MCH}$ receptors is also quite similar to orexin receptors indicating similar connections (Saito et al., 2001). In contrast to orexincontaining neurons, $\mathrm{MCH}$ neurons remain viable in human narcolepsy and in the orexin-ataxin-3 mice (Fig. $1 H$ ). The $\mathrm{MCH}$ 
Table 3. Number of bouts of the five vigilance states during the $12 \mathrm{~h}$ day and night periods

\begin{tabular}{|c|c|c|c|c|c|c|}
\hline & \multirow[b]{2}{*}{ Group } & \multicolumn{5}{|l|}{ Number of bouts } \\
\hline & & Cataplexy & REM sleep & Wake & Non-REM sleep & Sleep attacks \\
\hline \multicolumn{7}{|c|}{ During the night } \\
\hline 1 & WT $(n=5)$ & NA & $17.60(1.60)$ & $81.6(12.37)^{\ddagger}$ & $80.40(11.85)$ & NA \\
\hline 2 & No rAAV $(n=7)$ & $16.36(2.28)$ & $30.50(7.57)$ & $115.64(9.28)$ & $88.14(10.31)$ & $19.71(3.44)$ \\
\hline 3 & rAAV-GFP $(n=10)$ & $17.15(2.89)$ & $23.35(3.37)$ & $130.9(10.71)$ & $92.95(12.67)$ & $23.1(3.34)$ \\
\hline 4 & rAAV-orexin in striatum $(n=9)$ & $16.44(3.58)$ & $25.11(4.75)$ & $129.56(8.09)$ & $81.72(10.98)$ & $36.33(7.48)^{\S}$ \\
\hline 5 & rAAV-MCH-orexin ( $30 \%$ of MCH neurons) $(n=9)$ & $21.89(4.06)$ & $27.56(4.32)$ & $120.56(7.30)$ & $78.72(10.26)$ & $26.28(4.36)$ \\
\hline 6 & rAAV-MCH-orexin ( $65 \%$ of $\mathrm{MCH}$ neurons) $(n=7)$ & $28.21(4.22)$ & $27.07(3.05)$ & $148.64(11.37)$ & $81.50(5.81)$ & $47.71(8.19)^{\S \S}$ \\
\hline 7 & Dilute rAAV-orexin in $\mathrm{LH}(n=6)$ & $8.67(1.35)$ & $21.92(2.87)$ & $122.67(8.84)$ & $98.08(9.01)$ & $17.50(2.39)$ \\
\hline 8 & rAAV-orexin in LH $(n=11)$ & $3.96(0.56)^{*}$ & $37.73(1.87) \dagger$ & $114.05(7.03)$ & $96.68(5.70)$ & $17.18(3.22)$ \\
\hline 9 & rAAV-orexin in ZI $(n=8)$ & $6.06(1.33)^{* *}$ & $35.88(4.06)$ & $123.13(6.14)$ & $107.50(7.08)$ & $11.94(1.65)$ \\
\hline \multicolumn{7}{|c|}{ During the day } \\
\hline 1 & WT $(n=5)$ & NA & $62.40(3.45)$ & $149.80(8.47)$ & $151.50(8.13)$ & NA \\
\hline 2 & No rAAV $(n=7)$ & $6.64(2.29)$ & $77.43(4.61)$ & $169.50(7.06)$ & $168.50(5.16)$ & $15.79(3.08)$ \\
\hline 3 & $\operatorname{rAAV-GFP}(n=10)$ & $3.34(0.75)$ & $53.25(6.34)^{\|}$ & $153.7(10.32)$ & $152.10(11.68)$ & $4.15(1.24)$ \\
\hline 4 & rAAV-orexin in striatum $(n=9)$ & $4.56(0.86)$ & $62.78(4.03)$ & $166.94(4.74)$ & $159.17(3.74)$ & $11.83(2.04)$ \\
\hline 5 & rAAV-MCH-orexin (30\% of MCH neurons) $(n=9)$ & $3.17(0.49)$ & $80.44(5.74)$ & $153.78(7.85)$ & $157.11(9.21)$ & $6.89(2.01)$ \\
\hline 6 & rAAV-MCH-orexin ( $65 \%$ of MCH neurons) $(n=7)$ & $4.93(1.44)$ & $63.00(7.01)$ & $144.00(6.71)$ & $136.86(8.57)$ & $9.36(2.41)$ \\
\hline 7 & Dilute rAAV-orexin in LH $(n=6)$ & $0.833(0.28)^{9}$ & $65.92(5.38)$ & $169.50(6.96)$ & $171.25(6.75)$ & $2.67(0.76)$ \\
\hline 8 & rAAV-orexin in LH $(n=11)$ & $1.409(0.43)^{q}$ & $76.50(3.96)$ & $156.09(7.22)$ & $156.00(6.99$ & $10.55(1.97)$ \\
\hline 9 & rAAV-orexin in ZI $(n=8)$ & $0.625(0.23)^{9}$ & $79.19(5.01)$ & $165.38(6.99)$ & $167.50(6.98)$ & $3.63(0.72)$ \\
\hline
\end{tabular}

Values represent number \pm SEM. Each vigilance state was identified, and the average number during the $12 \mathrm{~h}$ day and night periods was determined for each group. Cataplexy and sleep attacks did not occur in WT mice and is not applicable (NA).

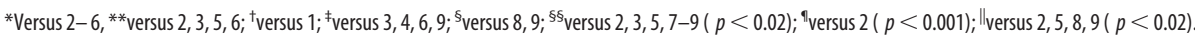

Table 4. Length of bouts of the five vigilance states during the $12 \mathrm{~h}$ day and night periods

\begin{tabular}{|c|c|c|c|c|c|c|}
\hline & & Length of bouts & & & & \\
\hline & Group & Cataplexy & REM sleep & Wake & Non-REM sleep & Sleep attacks \\
\hline During & & & & & & \\
\hline 1 & WT $(n=5)$ & NA & $59.02(3.21)$ & $449.53(75.95)^{\ddagger}$ & $129.07(9.83)$ & NA \\
\hline 2 & No rAAV $(n=7)$ & $79.29(7.26)$ & $71.31(5.70)$ & $264.27(24.10)$ & $118.95(9.96)$ & $38.10(1.86)$ \\
\hline 3 & rAAV-GFP $(n=10)$ & $73.52(4.8)$ & $64.12(3.79)$ & $241.29(27.56)$ & $119.61(6.19)$ & $35.75(4.1)$ \\
\hline 4 & rAAV-orexin in striatum $(n=9)$ & $99.09(4.13)$ & $53.09(2.04)^{\dagger}$ & $233.43(20.10)$ & $130.17(6.70)$ & $37.01(3.18)$ \\
\hline 5 & rAAV-MCH-orexin ( $30 \%$ of MCH neurons) $(n=9)$ & $81.49(4.80)$ & $51.08(4.05)^{\dagger+}$ & $261.75(28.25)$ & $116.34(7.46)$ & $35.65(2.04)$ \\
\hline 6 & rAAV-MCH-orexin ( $65 \%$ of MCH neurons) $(n=7)$ & $58.33(4.88)^{*}$ & $41.46(23.55)^{\dagger+\dagger}$ & $216.77(27.1)$ & $105.38(7.86)$ & $33.16(2.32)$ \\
\hline 7 & Dilute rAAV-orexin in LH $(n=6)$ & $87.64(7.69)$ & $57.83(2.2)$ & $259.86(24.70)$ & $104.32(8.32)$ & $30.77(2.84)$ \\
\hline 8 & rAAV-orexin in LH $(n=11)$ & $53.62(6.64)^{* *}$ & $50.79(1.33)^{\dagger \dagger}$ & $261.51(22.26)$ & $123.25(4.94)$ & $34.55(2.51)$ \\
\hline 9 & rAAV-orexin in ZI $(n=8)$ & $44.69(8.02)^{* *}$ & $54.77(2.97)^{\dagger}$ & $234.02(20.04)$ & $118.62(4.41)$ & $37.02(2.69)$ \\
\hline During & & & & & & \\
\hline 1 & WT $(n=5)$ & NA & $63.14(3.70)^{\natural}$ & $105.54(6.54)$ & $157.67(8.45)$ & NA \\
\hline 2 & No rAAV $(n=7)$ & $49.29(13.87)$ & $56.43(2.57)^{\natural}$ & $96.22(4.24)$ & $130.40(5.17)$ & $31.5(2.47)$ \\
\hline 3 & rAAV-GFP $(n=10)$ & $82.24(13.92)$ & $48.15(3.81)$ & $113.10(14.29)$ & $128.97(9.2)$ & $23.15(2.2)$ \\
\hline 4 & rAAV-orexin in striatum $(n=9)$ & $86.68(5.35)$ & $46.37(1.23)$ & $96.51(4.09)$ & $147.67(4.8)$ & $34.84(1.64)$ \\
\hline 5 & rAAV-MCH-orexin ( $30 \%$ of MCH neurons) $(n=9)$ & $61.32(8.24)$ & $40.75(1.57)$ & $114.48(8.79)$ & $146.93(9.6)$ & $28.67(4.02)$ \\
\hline 6 & rAAV-MCH-orexin (65\% of MCH neurons) $(n=7)$ & $50.82(2.33)$ & $37.84(2.56)$ & $133.41(10.85)$ & $158.89(9.33)$ & $30.96(6.34)$ \\
\hline 7 & Dilute rAAV-orexin in LH $(n=6)$ & $50.50(18.79)$ & $48.65(1.99)$ & $107.19(6.30)$ & $127.69(4.44)$ & $25.73(4.85)$ \\
\hline 8 & rAAV-orexin in LH $(n=11)$ & $28.61(7.66)^{\S}$ & $47.36(1.43)$ & $118.17(13.81)$ & $140.22(4.98)$ & $30.22(1.97)$ \\
\hline 9 & rAAV-orexin in ZI $(n=8)$ & $22.50(9.80)^{\S}$ & $43.22(1.47)$ & $106.77(9.64)$ & $133.16(3.23)$ & $24.56(4.22)$ \\
\hline
\end{tabular}

Values represent length (in seconds) \pm SEM. Each vigilance state was identified in 12 s epochs, and average length of the bouts during the $12 \mathrm{~h}$ day and night periods was determined for each group. Cataplexy and sleep attacks did not occur in WT mice and is not applicable (NA).

${ }^{*}$ Versus 4,$7 ;{ }^{* *}$ versus $2-5,7 ;{ }^{\dagger}$ versus $2 ;{ }^{+\dagger}$ versus 2,$3 ;{ }^{+1+}$ versus $1,2,3,7 ;{ }^{\ddagger}$ versus $2-9(p<0.003) ;{ }^{5}$ versus 3,$4 ;{ }^{*}$ versus $3-9(p<0.002)$.

neurons are active primarily during REM sleep (Hassani et al., 2009), a time when muscle tone is absent. There is no muscle tone during cataplexy either and we reasoned that by coexpressing orexin in $\mathrm{MCH}$ neurons the activity of the $\mathrm{MCH}$ neurons might release orexin onto appropriate target sites and abort cataplexy. Indeed, orexin was present in the CSF of the MCH plus orexin group, indicating release of the orexin, but cataplexy was not blocked. Instead, there were more sleep attacks at night, suggesting that targeting $\mathrm{MCH}$ neurons could worsen narcoleptic symptoms.

The effects on cataplexy were also dose dependent. In one group, diluted rAAV-orexin was administered to the LH, resulting in $45 \%$ of orexin-A-ir neurons as WT and one-half as much
orexin-A in the CSF as WT mice. The dilute rAAV-orexin infected fewer neurons. However, with viral transfer, it is not possible to control for how many copies of the gene get inserted into each cell. Nevertheless, cataplexy was reduced even with one-half as many orexin neurons as WT mice. However, in the striatum and one of the $\mathrm{MCH}$ groups, the number of neurons that synthesized orexin was not significantly different from WT, and yet cataplexy was not affected. This indicates that it is not sufficient to restock the brain with the normal number of orexin neurons. Rather, the right number of orexin neurons have to project to downstream targets that regulate the behavior. Indeed, in the three groups in which cataplexy was decreased, orexin-A-ir fibers were seen in the same regions as in WT mice. With more orexin 


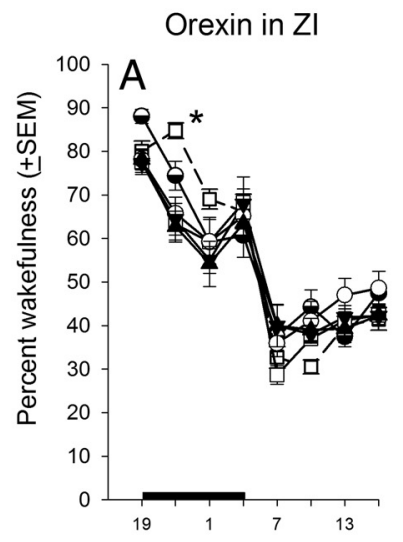

Orexin in $\mathrm{MCH}$ neurons
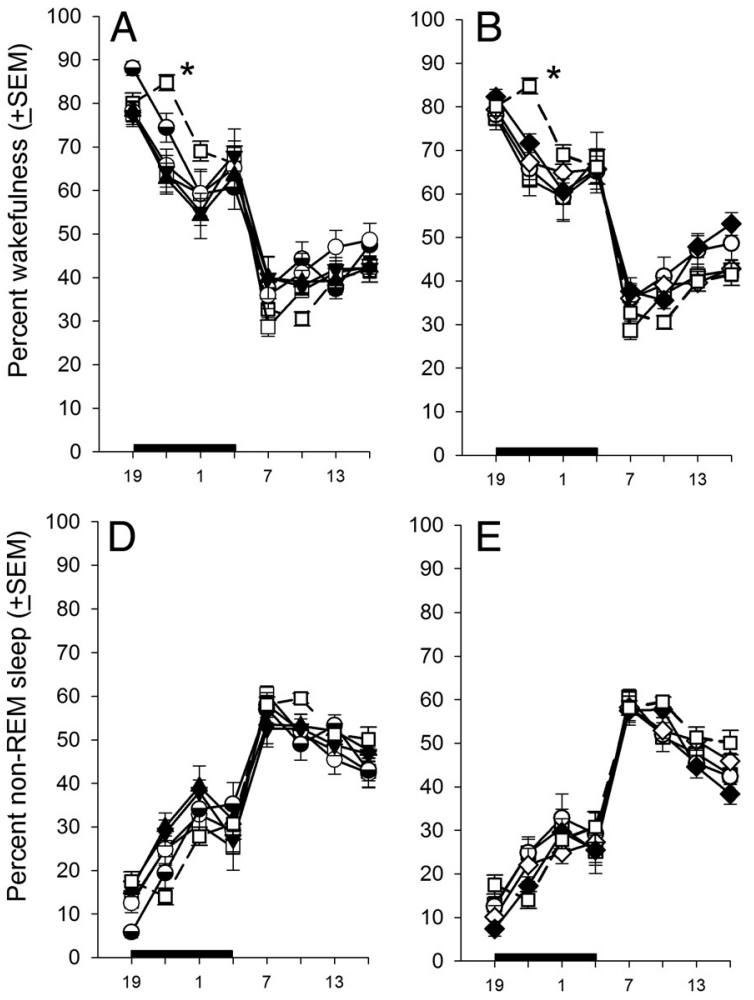

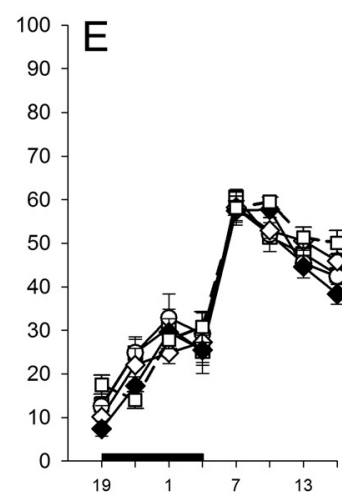

Time in $3 \mathrm{~h}$ blocks

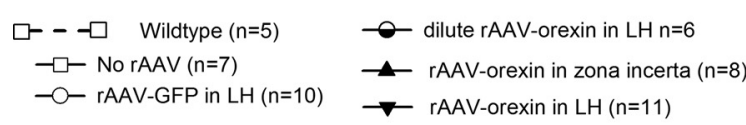

$\diamond-$ rAAV-MCH-orexin (30\% of $\mathrm{MCH}$ neurons) $(n=9)$

rAAV-MCH-orexin

(65\% of $\mathrm{MCH}$ neurons)( $(n=7)$

rAAV-orexin in striatum $(n=9)$
Figure 7. Average percentage of wakefulness and non-REM sleep in orexin-ataxin-3 mice after rAAV gene transfer. $\boldsymbol{A}-\boldsymbol{F}$ summarize the average ( \pm SEM) percentage of wakefulness or non-REM sleep at $3 \mathrm{~h}$ intervals across the $24 \mathrm{~h}$ period. The data for WT mice are given for comparison. One-way ANOVA followed by Dunnett's post hoc test with WT as the control group, $p<0.05$. The asterisk represents significant difference of the WT group compared with all groups except the dilute rAAV-orexin (half-filled circle) and rAAV-MCH-orexin 65\% (filled diamond) groups. neurons in the appropriate brain site, there is likely to be a synergistic action at downstream targets resulting in a greater effect on behavior. There might be differences in production of the peptide in different neuronal phenotypes. However, ultimately, release of the peptide at target sites affects behavior. Here, we have shown that CSF levels of orexin-A in mice in the rAAV-orexin-LH and rAAVorexin-ZI groups is similar to WT mice.

Cataplexy is an important diagnostic symptom of narcolepsy. Other symptoms include excessive daytime sleepiness, sleep attacks, and hypnagogic hallucinations. Cataplexy, sleepiness, and sleep attacks can be reliably measured in rodents as was done in the present study. However, only cataplexy was affected by the gene transfer, suggesting that the cataplexy circuit may be separate. Moreover, the results of the present study indicate that the circuit underlying cataplexy may be independent of the circuit responsible for the loss of muscle tone during REM sleep since REM sleep was decreased in some groups but cataplexy was not reduced.

rAAV is a virus and, although infrequent, may generate an immune response. Non-REM sleep is increased during a host defense reaction (Krueger et al., 2003). In the present study, three weeks after virus delivery, there was no change in waking or non-REM sleep in any of the mice given the rAAV, suggesting a negligible cytokine response of the rAAV. However, REM sleep was decreased in mice given the control vector compared with no-rAAV mice, indicating sensitivity of this sleep stage to the virus or the GFP reporter. REM sleep is usually

Table 5. Percentage of sleep-wake states during $12 \mathrm{~h}$ day and night cycles

\begin{tabular}{|c|c|c|c|c|c|c|}
\hline & Group & Cataplexy & REM & Wake & Non-REM sleep & Sleep attacks \\
\hline \multicolumn{7}{|l|}{ Night } \\
\hline 1 & $\mathrm{WT}(n=5)$ & NA & $2.40(0.18)$ & $75.01(1.62)$ & $22.51(1.65)$ & NA \\
\hline 2 & No-rAAV $(n=7)$ & $3.16(0.62)$ & $4.64(0.67)$ & $67.06(2.27)$ & $23.37(1.91)$ & $1.76(0.35)$ \\
\hline 3 & rAAV-GFP $(n=10)$ & $2.96(0.57)$ & $3.32(0.46)$ & $67.08(2.87)$ & $24.84(2.89)$ & $1.80(0.31)$ \\
\hline 4 & rAAV-orexin in striatum $(n=9)$ & $3.76(0.81)$ & $3.25(0.67)$ & $66.45(1.96)$ & $23.60(2.26)$ & $2.93(0.46)^{* * *}$ \\
\hline 5 & rAAV-MCH-orexin (30\% MCH neurons) $(n=9)$ & $3.88(0.61)$ & $3.46(0.60)$ & $69.30(2.64)$ & $21.07(2.51)$ & $2.28(0.46)$ \\
\hline 6 & rAAV-MCH-orexin (65\% MCH neurons) $(n=7)$ & $4.06(0.71)$ & $2.68(0.41)$ & $70.02(2.12)$ & $19.90(2.29)$ & $3.35(0.49)^{* *}$ \\
\hline 7 & Dilute rAAV-orexin $(n=6)$ & $1.66(0.22)$ & $2.89(0.35)$ & $70.57(2.67)$ & $23.64(2.64)$ & $1.25(0.21)$ \\
\hline 8 & rAAV-orexin in LH $(n=11)$ & $0.49(0.06)^{*}$ & $4.49(0.26)$ & $66.17(1.49)$ & $27.55(1.17)$ & $1.30(0.25)$ \\
\hline 9 & rAAV-orexin in ZI $(n=8)$ & $0.77(0.18)^{*}$ & $4.43(0.37)$ & $64.62(2.42)$ & $29.17(2.19)$ & $1.01(0.15)$ \\
\hline \multicolumn{7}{|l|}{ Day } \\
\hline 1 & $\mathrm{WT}(n=5)$ & NA & $9.11(0.52)$ & $36.13(0.56)$ & $54.74(0.98)$ & NA \\
\hline 2 & no-rAAV $(n=7)$ & $0.92(0.34)$ & $10.03(0.39)$ & $37.31(0.54)$ & $50.56(0.73)$ & $1.18(0.28)$ \\
\hline 3 & rAAV-GFP $(n=10)$ & $0.79(0.19)$ & $6.32(0.57)^{\S \neq}$ & $43.15(2.87)$ & $49.44(2.62)$ & $0.30(0.09)$ \\
\hline 4 & rAAV-orexin in striatum $(n=9)$ & $0.92(0.15)$ & $6.78(0.45)^{\S}$ & $37.13(1.47)$ & $54.24(1.37)$ & $0.93(0.19)$ \\
\hline 5 & rAAV-MCH-orexin (30\% MCH neurons) $(n=9)$ & $0.48(0.08)$ & $7.7(0.71)$ & $39.38(1.37)$ & $51.90(1.38)$ & $0.55(0.21)$ \\
\hline 6 & rAAV-MCH-orexin (65\% MCH neurons) $(n=7)$ & $0.63(0.19)$ & $5.55(0.77)^{\S \ddagger}$ & $43.53(2.23)$ & $49.55(2.12)$ & $0.74(0.20)$ \\
\hline 7 & Dilute rAAV-orexin $(n=6)$ & $0.15(0.05)^{\S}$ & $7.45(0.59)$ & $41.66(1.29)$ & $50.56(1.26)$ & $0.17(0.04)$ \\
\hline 8 & rAAV-orexin in $\mathrm{LH}(n=11)$ & $0.16(0.06)^{\S}$ & $8.44(0.50)$ & $40.50(1.99)$ & $50.13(1.77)$ & $0.77(0.15)$ \\
\hline 9 & rAAV-orexin in ZI $(n=8)$ & $0.08(0.04)^{\S t}$ & $7.99(0.58)$ & $40.13(2.26)$ & $51.56(1.97)$ & $0.24(0.06)$ \\
\hline
\end{tabular}

${ }^{*}$ Versus groups 2-6 $(p<0.012) ;{ }^{* *}$ versus group $2,3,7-9(p<0.05) ;{ }^{* * *}$ versus groups $7-9(p<0.04) ;{ }^{\dagger}$ versus groups $2-4(p<0.05) ;{ }^{\ddagger}$ versus group $1(p<0.05) ;{ }^{\S}$ versus group $2(p<0.05)$. 

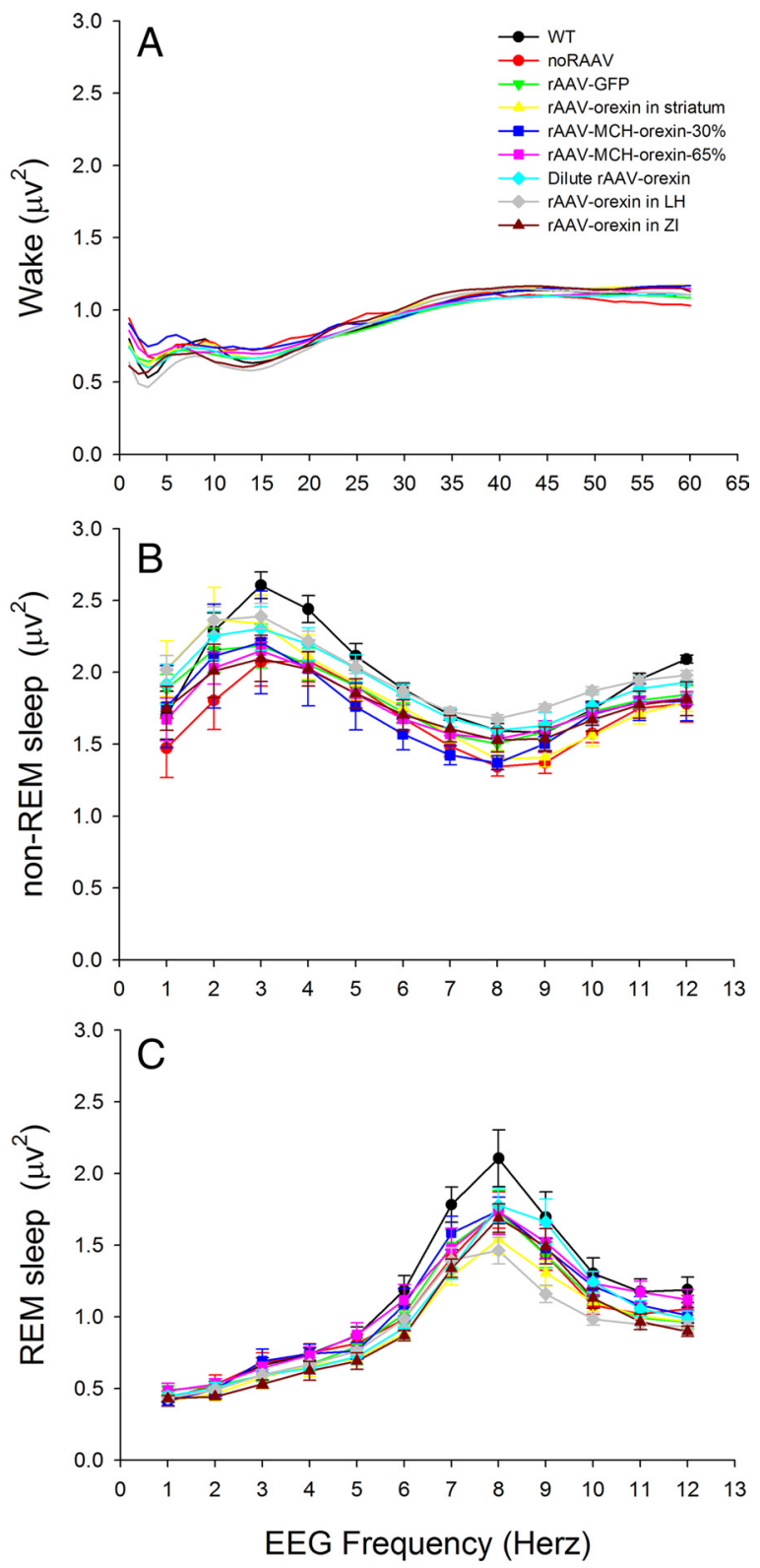

Figure 8. Spectrum of frequencies of the EEG at night during wakefulness $(\boldsymbol{A})$, non-REM sleep $(\boldsymbol{B})$, and REM sleep $(\boldsymbol{C})$ in WT and orexin-ataxin-3 mice given rAAV. EEG spectral analysis was performed using the fast Fourier transform method (SleepSign Software; Kissei Comtec) and the power (in square microvolts) at each $1.0 \mathrm{~Hz}$ bin was determined. Each sleep-wake state has a characteristic EEG frequency with faster $(>20 \mathrm{~Hz}$ ) frequencies occurring during waking and slower $(1-4 \mathrm{~Hz})$ frequencies during non-REM sleep. During REM sleep, the EEG oscillates between 6 and $12 \mathrm{~Hz}$. Orexin gene transfer did not shift the frequency or change the EEG power compared with animals receiving no-rAAV. The data symbols or the SE bars are not depicted in A for purposes of clarity.

decreased under many circumstances, but such a decrease has not been shown to adversely affect behavior. For instance, tricyclic antidepressants and monoamine oxidase inhibitors decrease REM sleep, and yet they have been used as a treatment for depression for almost 40 years.

Previously, we used a different viral vector, herpes simplex virus-1 (HSV-1), to reduce cataplexy (Liu et al., 2008). HSV-1 has a $4 \mathrm{~d}$ life span, whereas AAV-mediated gene transfer is long term, with gene expression found in CNS neurons for periods in excess of a year, both in rodent and human brains (van den Pol et al., 2004; Mueller and Flotte, 2008), with minimal adverse side ef- fects. AAV is currently being used in a large number of clinical trials for gene transfer in humans with minimal adverse effects and success in some patients for alleviating symptoms of various CNS and non-CNS diseases (Kaplitt et al., 2007; Simonelli et al., 2010). The previous study transferred the orexin gene into neurons of orexin knock-out mice in which the underlying circuitry was intact. In the present study, the orexin neurons had died (emulating human narcolepsy), requiring surrogate neurons to decrease narcoleptic symptoms.

Our study has identified the ZI as a link between cortical-limbic and downstream pontine regions linked to cataplexy. Inputs to the ZI from limbic-motor regions were active during waking as determined by c-Fos, which is consistent with evidence that cataplexy is usually triggered by strong emotions. During cataplexy, humans and canines with narcolepsy are usually awake and aware of their surroundings (Siegel and Boehmer, 2006). In orexin knock-out mice, cataplexy is also distinct state (Thankachan et al., 2009). We suggest that the loss of orexin or the orexin-2 receptor may destabilize neuronal activity in the ZI. The orexin-2 receptor is present in the ZI (Marcus et al., 2001). A mutation of this receptor is linked to cataplexy in canines (Lin et al., 1999) and orexin-receptor-2 knock-out mice have cataplexy but orexin-receptor-1 knock-out mice do not (Willie et al., 2003). Neurons that are active during cataplexy have been found in the medial medulla oblongata (Siegel et al., 1991), tuberomammillary nucleus (John et al., 2004), and the amygdala (Gulyani et al., 2002). Such neurons might also be present in the ZI.

We also determined that the ZI innervates the locus ceruleus. LC neurons are active during waking but silent during REM sleep and cataplexy (Wu et al., 1999). Cataplexy can be triggered with optogenetic inhibition of LC neuronal activity (Carter et al., 2010). We suggest that, during purposeful movements such as running, grooming, or eating, the amygdala-ZI-LC circuit is robustly activated as measured by c-Fos and electrophysiology studies (Koyama et al., 2003). In WT mice, orexin neurons have widespread ascending and descending projections including to the motor cortex, amygdala, ZI, and LC (Peyron et al., 2000; Marcus et al., 2001), which likely serves to stabilize neuronal activity. When orexin is missing or the orexin-2 receptor is dysfunctional (mutated or missing), then such neuronal activity converging onto the LC may become destabilized, which then triggers cataplexy. We determined that introduction of orexin into the ZI, which is upstream of the LC, blocks cataplexy. We suggest that other neurons, such as the $\mathrm{MCH}$ neurons that also project to the LC, do not block cataplexy, even when they contain orexin, because they are silent during waking. Thus, circuit stabilization is achieved by inserting orexin into neurons that are active during waking and also heavily innervate the LC.

Ectopic expression of orexin in the orexin-ataxin-3 mice rescues the phenotype, but only after constitutive expression of orexin in every cell from conception (Mieda et al., 2004). Such a rescue is not feasible in humans. Intracerebroventricular injections of orexin-A in orexin-ataxin-3 mice also rescues the phenotype (Mieda et al., 2004). However, the concentration of the peptide that was injected in that study ( $3 \mathrm{nM})$ was at least a hundred thousand-fold higher than the levels evident in the CSF of WT mice. Thus, there is a need to explore methods that reintroduce the orexin peptide, but in a discrete circuit, and at physiological levels.

Identification of the ZI as a target for orexin expression will aid pharmacological treatments. There is the promise of new treatments, such as nasal inhalation, that deliver orexin (Deadwyler et al., 2007). Such treatments could benefit from delivery of the orexin to specific brain sites and into specific neuronal phe- 

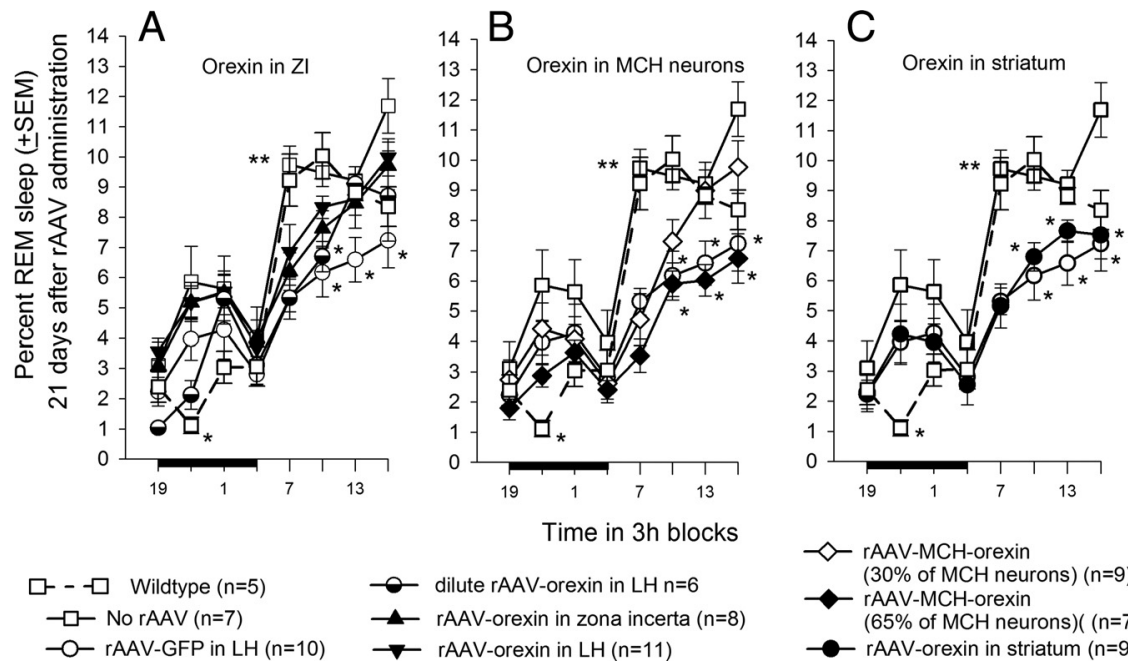

Figure 9. Average ( \pm SEM) percentage of REM sleep over $24 \mathrm{~h}$ in WT and orexin-ataxin-3 mice. The data for WT mice are given for comparison. The bar graphs in $\boldsymbol{A}-\boldsymbol{C}$ summarize the average ( \pm SEM) percentage of REM sleep during the $12 \mathrm{~h}$ day and night periods. One-way ANOVA followed by Dunnett's post hoc test, $p<0.05 .{ }^{*}$ Compared with no-rAAV group; ${ }^{* *}$ no-rAAV versus all groups except WT.
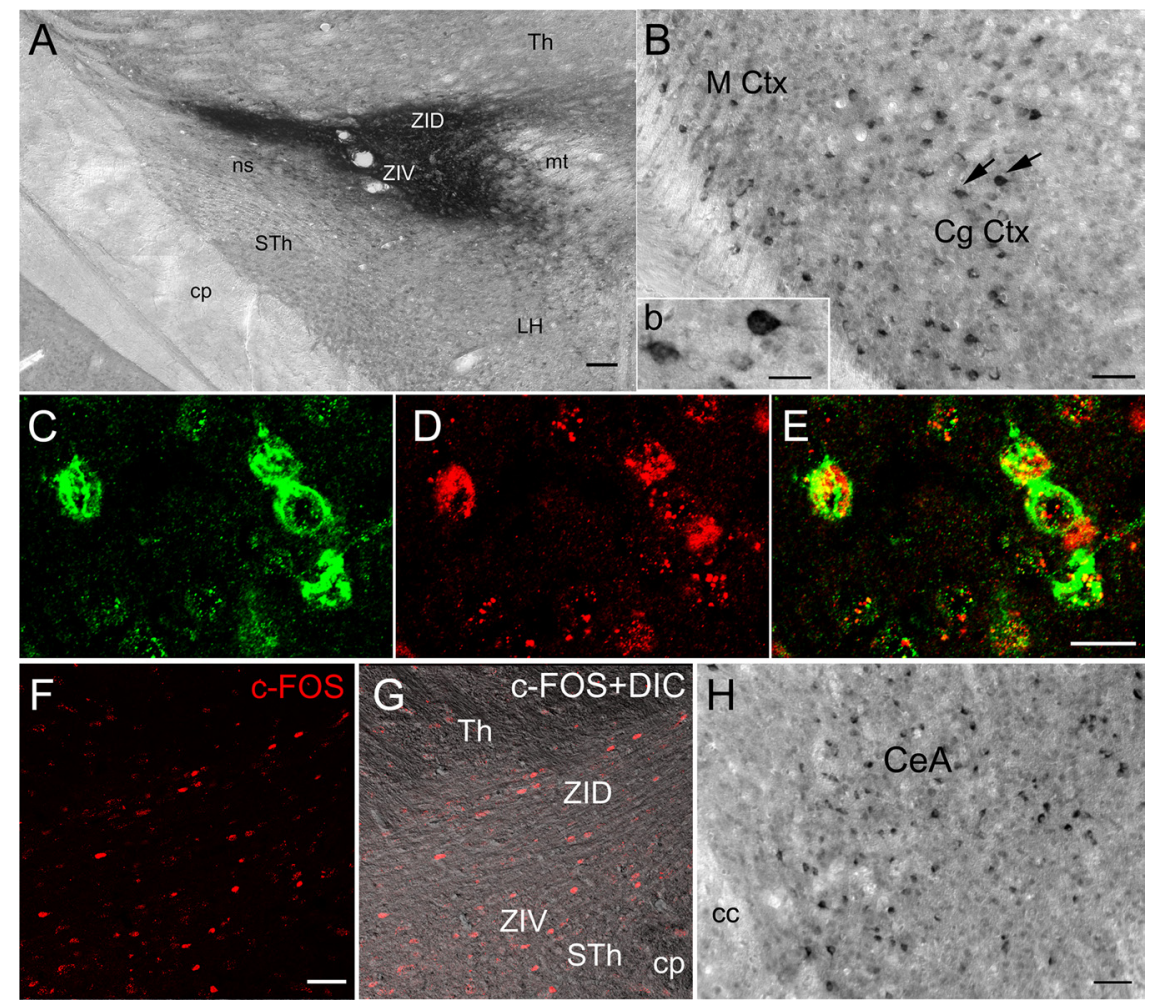

Figure 10. Inputs to the zona incerta from the cingulate cortex and the amygdala are c-Fos positive. The retrograde tracer (Tb was injected into the zona incerta $(\boldsymbol{A})$ (unilateral injection; $50 \mathrm{nl} ; 2 \%$ solution), and $7 \mathrm{~d}$ later the orexin-ataxin- 3 mice were kept awake for $6 \mathrm{~h}$ and then killed (overdose of Nembutal). Neurons in the cingulate cortex ( $\boldsymbol{B}$; inset $\boldsymbol{b}$ ) and the amygdala $(\boldsymbol{H})$ were filled with the tracer, indicating that these neurons project to the zona incerta. Inset $\boldsymbol{b}$ depicts the neurons identified by arrows in $\boldsymbol{B}$. Adjacent sections were processed for visualization of c-Fos, a marker of neuronal activity, and the retrogradely labeled neurons in the cingulate cortex were positive for $\mathrm{CTb}(\boldsymbol{C})$ and $\mathrm{C}-\mathrm{Fos}(\boldsymbol{D})$, indicating that these neurons were active during waking. $\boldsymbol{E}$ is a merge of neurons depicted in $\boldsymbol{C}$ and $\boldsymbol{D}$. The contralateral zona incerta contained numerous c-Fos-positive neurons, indicating that this region is also active during waking. $\boldsymbol{F}$ depicts c-Fos-immunoreactive neurons in the $Z \mathbf{Z l}$, whereas $\mathbf{G}$ depicts the same section under differential contrast (DIC) to highlight the tissue section. Scale bars: $\boldsymbol{A}, 100 \mu \mathrm{m} ; \boldsymbol{B}, 50 \mu \mathrm{m}$; inset $\boldsymbol{b}, 20 \mu \mathrm{m}$; (in $\boldsymbol{E}) \boldsymbol{C}-\boldsymbol{E}, 20 \mu \mathrm{m}$; (in $\boldsymbol{F}) \boldsymbol{F}, \boldsymbol{G}, 50 \mu \mathrm{m} ; \boldsymbol{H}, 50 \mu \mathrm{m}$. Abbreviations: CeA, Central nucleus of the amygdala; $c c$, corpus callosum; $\mathrm{CgCtx}$, cingulated cortex; $c p$, cerebral peduncle; DIC, differential interference contrast; Th, thalamus; LH, lateral hypothalamus; MCtx, motor cortex; mt, mammillothalamic tract; STH, subthalamus; ZID, zona incerta dorsal; ZIV, zona incerta ventral.

notypes. The gene transfer method represents a cost-effective tool to rapidly identify such sites and help delineate the circuitry.

\section{References}

Aldrich MS (1993) The neurobiology of narcolepsycataplexy. Prog Neurobiol 41:533-541

Bittencourt JC, Presse F, Arias C, Peto C, Vaughan J, Nahon JL, Vale W, Sawchenko PE (1992) The melanin-concentrating hormone system of the rat brain: an immuno- and hybridization histochemical characterization. J Comp Neurol 319:218-245.

Blouin AM, Thannickal TC, Worley PF, Baraban JM, Reti IM, Siegel JM (2005) Narp immunostaining of human hypocretin (orexin) neurons: loss in narcolepsy. Neurology 65:1189-1192.

Carter ME, Yizhar O, Chikahisa S, Nguyen $\mathrm{H}$, Adamantidis A, Nishino S, Deisseroth K, de Lecea L (2010) Tuning arousal with optogenetic modulation of locus coeruleus neurons. Nat Neurosci 13:1526-1533.

Chemelli RM, Willie JT, Sinton CM, Elmquist JK, Scammell T, Lee C, Richardson JA, Williams SC, Xiong Y, Kisanuki Y, Fitch TE, Nakazato M, Hammer RE, Saper CB, Yanagisawa M (1999) Narcolepsy in orexin knockout mice: molecular genetics of sleep regulation. Cell 98:437-451.

Crocker A, España RA, Papadopoulou M, Saper CB, Faraco J, Sakurai T, Honda M, Mignot E, Scammell TE (2005) Concomitant loss of dynorphin, NARP, and orexin in narcolepsy. Neurology 65:1184-1188.

Deadwyler SA, Porrino L, Siegel JM, Hampson RE (2007) Systemic and nasal delivery of orexin-A (Hypocretin-1) reduces the effects of sleep deprivation on cognitive performance in nonhuman primates. J Neurosci 27:14239-14247.

de Lecea L, Kilduff TS, Peyron C, Gao X, Foye PE, Danielson PE, Fukuhara C, Battenberg EL, Gautvik VT, Bartlett FS 2nd, Frankel WN, van den Pol AN, Bloom FE, Gautvik KM, Sutcliffe JG (1998) The hypocretins: hypothalamus-specific peptides with neuroexcitatory activity. Proc Natl Acad Sci U S A 95:322-327.

Fischer DF, Hol EM, Hobo B, van Leeuwen FW (2006) Alzheimer-associated APP +1 transgenic mice: frameshift beta-amyloid precursor protein is secreted in cerebrospinal fluid without inducing neuropathology. Neurobiol Aging 27:1445-1450.

Gulyani S, Wu MF, Nienhuis R, John J, Siegel JM (2002) Cataplexy-related neurons in the amygdala of the narcoleptic dog. Neuroscience 112:355-365.

Hara J, Beuckmann CT, Nambu T, Willie JT, Chemelli RM, Sinton CM, Sugiyama F, Yagami K, Goto K, Yanagisawa M, Sakurai T (2001) Genetic ablation of orexin neurons in mice results in narcolepsy, hypophagia, and obesity. Neuron 30:345-354.

Hassani OK, Lee MG, Jones BE (2009) Melaninconcentrating hormone neurons discharge in a reciprocal manner to orexin neurons across the sleep-wake cycle. Proc Natl Acad Sci U S A 106:2418-2422.

John J, Wu MF, Boehmer LN, Siegel JM (2004) Cataplexy-active neurons in the hypothala- 
mus: implications for the role of histamine in sleep and waking behavior. Neuron 42:619-634.

Kaplitt MG, Feigin A, Tang C, Fitzsimons HL, Mattis P, Lawlor PA, Bland RJ, Young D, Strybing K, Eidelberg D, During MJ (2007) Safety and tolerability of gene therapy with an adeno-associated virus (AAV) borne GAD gene for Parkinson's disease: an open label, phase I trial. Lancet 369:2097-2105.

Koyama Y, Takahashi K, Kodama T, Kayama Y (2003) State-dependent activity of neurons in the perifornical hypothalamic area during sleep and waking. Neuroscience 119:1209-1219.

Krueger JM, Majde JA, Obal F (2003) Sleep in host defense. Brain Behav Immun 17 [Suppl 1]:S41-S47.

Lin L, Faraco J, Li R, Kadotani H, Rogers W, Lin X, Qiu X, de Jong PJ, Nishino S, Mignot E (1999) The sleep disorder canine narcolepsy is caused by a mutation in the hypocretin (orexin) receptor 2 gene. Cell 98:365-376.

Liu M, Thankachan S, Kaur S, Begum S, Blanco-Centurion C, Sakurai T, Yanagisawa M, Neve R, Shiromani PJ (2008) Orexin (hypocretin) gene transfer diminishes narcoleptic sleep behavior in mice. Eur J Neurosci 28:1382-1393.

Marcus JN, Aschkenasi CJ, Lee CE, Chemelli RM, Saper CB, Yanagisawa M, Elmquist JK (2001) Differential expression of orexin receptors 1 and 2 in the rat brain. J Comp Neurol 435:6-25.

Mieda M, Willie JT, Hara J, Sinton CM, Sakurai T, Yanagisawa M (2004) Orexin peptides prevent cataplexy and improve wakefulness in an orexin neuron-ablated model of narcolepsy in mice. Proc Natl Acad Sci U S A 101:4649-4654.

Mignot E (1998) Genetic and familial aspects of narcolepsy. Neurology 50:S16-S22.

Mueller C, Flotte TR (2008) Clinical gene therapy using recombinant adeno-associated virus vectors. Gene Ther 15:858-863.

Nishino S, Ripley B, Overeem S, Lammers GJ, Mignot E (2000) Hypocretin (orexin) deficiency in human narcolepsy. Lancet 355:39-40.

Peyron C, Tighe DK, van den Pol AN, de Lecea L, Heller HC, Sutcliffe JG, Kilduff TS (1998) Neurons containing hypocretin (orexin) project to multiple neuronal systems. J Neurosci 18:9996-10015.

Peyron C, Faraco J, Rogers W, Ripley B, Overeem S, Charnay Y, Nevsimalova S, Aldrich M, Reynolds D, Albin R, Li R, Hungs M, Pedrazzoli M, Padigaru M, Kucherlapati M, Fan J, Maki R, Lammers GJ, Bouras C, Kucherlapati R, et al. (2000) A mutation in a case of early onset narcolepsy and a generalized absence of hypocretin peptides in human narcoleptic brains. Nat Med 6:991-997.

Plaha P, Ben-Shlomo Y, Patel NK, Gill SS (2006) Stimulation of the caudal zona incerta is superior to stimulation of the subthalamic nucleus in improving contralateral parkinsonism. Brain 129:1732-1747.

Plaha P, Khan S, Gill SS (2008) Bilateral stimulation of the caudal zona incerta nucleus for tremor control. J Neurol Neurosurg Psychiatry 79:504-513.
Sagar SM, Sharp FR, Curran T (1988) Expression of c-Fos protein in brain: metabolic mapping at the cellular level. Science 240:1328-1331.

Saito Y, Cheng M, Leslie FM, Civelli O (2001) Expression of the melaninconcentrating hormone $(\mathrm{MCH})$ receptor mRNA in the rat brain. J Comp Neurol 435:26-40.

Sakurai T, Amemiya A, Ishii M, Matsuzaki I, Chemelli RM, Tanaka H, Williams SC, Richarson JA, Kozlowski GP, Wilson S, Arch JR, Buckingham RE, Haynes AC, Carr SA, Annan RS, McNulty DE, Liu WS, Terrett JA, Elshourbagy NA, Bergsma DJ, et al. (1998) Orexins and orexin receptors: a family of hypothalamic neuropeptides and $\mathrm{G}$ protein-coupled receptors that regulate feeding behavior. Cell 92:1.

Scammell TE, Willie JT, Guilleminault C, Siegel JM (2009) A consensus definition of cataplexy in mouse models of narcolepsy. Sleep 32:111-116.

Shiromani PJ, Xu M, Winston EM, Shiromani SN, Gerashchenko D, Weaver DR (2004) Sleep rhythmicity and homeostasis in mice with targeted disruption of mPeriod genes. Am J Physiol Regul Integr Comp Physiol 287:R47-R57.

Siegel JM, Boehmer LN (2006) Narcolepsy and the hypocretin systemwhere motion meets emotion. Nat Clin Pract Neurol 2:548-556.

Siegel JM, Nienhuis R, Fahringer HM, Paul R, Shiromani P, Dement WC, Mignot E, Chiu C (1991) Neuronal activity in narcolepsy: identification of cataplexy-related cells in the medial medulla. Science 252:1315-1318.

Simonelli F, Maguire AM, Testa F, Pierce EA, Mingozzi F, Bennicelli JL, Rossi S, Marshall K, Banfi S, Surace EM, Sun J, Redmond TM, Zhu X, Shindler KS, Ying GS, Ziviello C, Acerra C, Wright JF, McDonnell JW, High KA, et al. (2010) Gene therapy for Leber's congenital amaurosis is safe and effective through 1.5 years after vector administration. Mol Ther 18:643-650.

Thankachan S, Kaur S, Shiromani PJ (2009) Activity of pontine neurons during sleep and cataplexy in hypocretin knock-out mice. J Neurosci 29:1580-1585.

Thannickal TC, Moore RY, Nienhuis R, Ramanathan L, Gulyani S, Aldrich M, Cornford M, Siegel JM (2000) Reduced number of hypocretin neurons in human narcolepsy. Neuron 27:469-474.

van den Pol AN, Acuna-Goycolea C, Clark KR, Ghosh PK (2004) Physiological properties of hypothalamic MCH neurons identified with selective expression of reporter gene after recombinant virus infection. Neuron 42:635-652.

Willie JT, Chemelli RM, Sinton CM, Tokita S, Williams SC, Kisanuki YY, Marcus JN, Lee C, Elmquist JK, Kohlmeier KA, Leonard CS, Richardson JA, Hammer RE, Yanagisawa M (2003) Distinct narcolepsy syndromes in Orexin receptor-2 and Orexin null mice. Molecular genetic dissection of non-REM and REM sleep regulatory processes. Neuron 38:715-730.

Wu MF, Gulyani SA, Yau E, Mignot E, Phan B, Siegel JM (1999) Locus coeruleus neurons: cessation of activity during cataplexy. Neuroscience 91:1389-1399. 